\title{
The Lim1 oncogene as a new therapeutic target for metastatic human renal cell carcinoma
}

\author{
Imène Hamaidi ${ }^{1}$, Catherine Coquard ${ }^{1}$, Sabrina Danilin ${ }^{1,5}$, Valérian Dormoy ${ }^{1,6}$, Claire \\ Béraud ${ }^{2}$, Sylvie Rothhut ${ }^{1}$, Mariette Barthelmebs ${ }^{1}$, Véronique Lindner ${ }^{3}$, Hervé Lang ${ }^{4}$ \\ and Thierry Massfelder ${ }^{{ }^{*}}$
}

${ }^{1}$ INSERM UMR_S1113, Section of Cell Signalisation and Communication in Kidney and Prostate Cancer, INSERM and University of Strasbourg, School of Medicine, Fédération de Médecine Translationnelle de Strasbourg (FMTS), Strasbourg, 67085 France; ${ }^{2}$ UROLEAD SAS, School of Medicine, Strasbourg, 67085 France; ${ }^{3}$ Hôpitaux Universitaires de Strasbourg, Hôpital de Strasbourg-Hautepierre, Department of Pathology, Strasbourg, 67098 France; ${ }^{4}$ Hôpitaux Universitaires de Strasbourg, Nouvel Hôpital Civil, Department of Urology, Strasbourg, 67091 France

${ }^{5}$ Current address: Firalis, Huningue, 68330 France;

${ }^{6}$ Current address: INSERM UMR_S903, Université de Reims Champagne-Ardenne (URCA), CHU Maison Blanche, 45 rue Cognacq-Jay, 51092 Reims

${ }^{*}$ To whom correspondence should be addressed: Thierry Massfelder, Tel: 333-68-85-34-56; Fax: 333-68-85-34-59; E-mail: massfeld@unistra.fr

Abbreviations: RCC, renal cell carcinoma; CCC, conventional renal cell carcinoma; VHL, von Hippel-Lindau

Running title: Lim1 in metastatic renal cell carcinoma 


\section{Abstract}

Metastatic clear cell renal cell carcinoma (CCC) remains incurable despite advances in the development of anti-angiogenic targeted therapies and the emergence of immune checkpoints inhibitors. We have previously shown that the sonic hedgehog-Gli signaling pathway is oncogenic in CCC allowing us to identify the developmental Liml transcription factor as a Gli target and as a new oncogene in CCC regulating cell proliferation and apoptosis, and promoting tumor growth. In this previous study, preliminary in vitro results also suggested that Lim1 may be implicated in metastatic spread. Here we investigated the potential prometastatic role of Lim1 in advanced CCC (1) in vitro using a panel of CCC cell lines expressing or not the von Hippel-Lindau (VHL) tumor suppressor gene either naturally or by gene transfer and (2) ex vivo in $30 \mathrm{CCC}$ metastatic tissues including lymph nodes, lung, skin, bone and adrenal metastases and (3) in vivo, using a metastatic model by iv injection of siRNA-transfected cells into Balb/c nude. Our in vitro results reveal that Lim1 knockdown time-dependently decreased CCC cell motility, migration, invasion and clonogenicity by up to $50 \%$ regardless of their VHL status. Investigating the molecular machinery involved in these processes, we identified a large panel of Lim1 targets known to be involved in cell adhesion (paxillin, fibronectin), epithelial-mesenchymal transition (Twist1/2), snail), invasion (MMP1/2/3/8/9) and metastatic progression (CXCR4, SDF-1, ANG-1). Importantly, Lim1 was found constitutively expressed in all metastatic tissues. The H-score in metastatic tissues being significantly superior to the score in the corresponding primary tumor tissues $(P$ value $=$ 0.009). Furthermore, we showed that Lim1 silencing decreases pulmonary metastasis development in terms of number and size in the in vivo metastatic model of human CCC. Taken together, these experiments strengthen the potential therapeutic value of Lim1 targeting as a promising novel approach for treating metastatic human CCC. 
Key words: Lim1, human renal cell carcinoma, tumorigenesis, metastasis, invasion, mouse xenograft models 


\section{INTRODUCTION}

Renal cell carcinoma (RCC) is one of the most malignant tumors and clear cell RCC (CCC), among all subtypes of RCC, is the most common and aggressive one. At diagnosis, metastases are often already present, due to the asymptomatic nature of kidney cancer, and relapse after nephrectomy is common. ${ }^{1}$ RCC metastases are surgically difficult to remove. They are resistant to radiotherapy and systemic therapies including hormonotherapy, chemotherapy and immunotherapy based on interleukin-2 and interferon alpha. Several targeted therapies including the VEGF-neutralizing antibody bevacizumab, the receptor tyrosine kinase inhibitors sunitinib, sorafenib and axitinib, and more recently cabozantinib, and the mTOR inhibitors everolimus and temsirolimus have been approved for the treatment of metastatic RCC desease over the past 10 years. ${ }^{2}$ However, to date, metastatic RCC remains largely incurable. ${ }^{3}$ New therapeutic approaches are currently being evaluated based on immune checkpoint inhibitors anti-Programmed cell Death protein 1 (PD-1)/antiProgrammed Death-ligand 1 (PD-L1) and anti-Cytotoxic T-lymphocyte-associated antigen 4 (CTLA-4) antibodies, alone or in combination with targeted therapies; although gain have been observed with nivolumab (anti-PD-1) in terms of overall survival with these approaches, there are still no tumor regression and cure. ${ }^{4}$

We have previously shown the oncogenicity of the developmental signaling pathway sonic hedgehog (SHH)-Glioma-associated oncogene (Gli) and its orchestral role in stimulating other signaling pathways and markers, such as the phosphatidylinositol-3 kinase (PI3K)/Akt

pathway that we previously evidenced as an important pathway for kidney carcinogenesis. ${ }^{5,6}$ In addition, in this previous work, we have identified various Gli targets, among them the Lim1 transcription factor, that we have subsequently shown to be a new oncogene in human CCC. ${ }^{7}$ Lim1, a LIM homeobox protein, is an important actor during development as well, being already expressed at the gastrula stage and being involved thereafter in the head, in the 
uterus and the vagina development. ${ }^{8-13}$ In addition, Lim1 governs anterior mesendoderm, node, and midline development together with Otx2 (Orthodenticle homeobox 2), Foxa2 (Forkhead box A2), and its cofactor Ldb1 (LIM domain binding protein1), and is an important actor of kidney development. Indeed, it regulates the expression of genes from both proximal and distal kidney structures, ${ }^{14,15}$ being for example involved in the definition of the renal proximal tubule, from which $\mathrm{CCC}$ arises. In the adult in human, expression of Lim1 is retricted to some regions of the brain, the thymus and in the endometrial epithelium and stroma. ${ }^{8,16}$ Lim1 has been reported to be overexpressed in gastric and pancreatic cancers and in chronic leukemia ${ }^{17-19}$ and to be reactivated in nephroblastoma and in medulloblastoma. ${ }^{20,21}$ In addition, it has been identified as a susceptibility gene for hepatitis B virus-related hepatocellular carcinoma. ${ }^{22}$ Interestingly, in medulloblastoma, Lim1 was identified as a functional genomic driver for metastatic dissemination. ${ }^{21}$ In our previous work, we have shown that Lim1 is exclusively expressed in CCC tumors compared to normal corresponding tissues; the mechanisms underlying its oncogenic activities involved proliferative and antiapoptotic properties in vitro in cultured cells and on tumor growth in CCC-bearing nude mice models. Preliminary results also revealed that Lim1 may be involved in cell movements and thus that it may be part of the machinery leading to metastasis development. ${ }^{7}$ The mechanism of such potential pro-metastatic activity of Lim1 has to be fully defined.

Research on RCC invasion and metastasis mechanisms has a high priority due to the poor prognosis of patients with metastatic RCC disease. Recent works described that matrix metalloproteinases (MMPs) or enzymes that degrade components of the extracellular matrix and basement membrane, such as heparanase, are involved in advanced tumoral stages and that factors involved in epithelial-mesenchymal transition (EMT), such as Snail and Slug, are also involved in metastatic stages through down-regulation of E-cadherin and up-regulation of MMPs. ${ }^{23}$ We have shown that Lim1 is involved in the constitutive activation of oncogenic 
signaling pathways, including the PI3K/Akt pathway, that has also been shown to be linked to metastatic desease. ${ }^{6,24-26}$

The present work focused on the effect of Lim1 in migration and invasion of CCC cells both in vitro and in vivo, in addition to its clinical relevance. we illustrated that Lim1 promoted metastasis development. 


\section{RESULTS}

\section{Lim1 silencing inhibits cell movements in a panel of human CCC cell lines}

In our previous work, preliminary results showed that Lim1 is involved in cell movements in

2 CCC cell lines (786-0 and Caki1). We thus investigated this biological property in an additional panel of human CCC cell lines. No pharmacological inhibitors of Lim1 has yet been developed so that we silenced Lim1 expression using specific siRNAs.

In our previous study on Lim1 we used 3 siRNAs, siLhx1ex1, siLhx1ex2 and siLhx1ex3 targeting exon 1, 2 and 3 respectively. ${ }^{7}$ Similar results were obtained in this previous work with the 3 siRNA sets. Consistent with this observations, the in vitro experiments herein were performed with the same 3 sets of siRNAs. Only results with siLhx1ex2 (abbreviated siLhx1) will be depicted.

Lim1 knockdown efficiency with siLhx1 (50nM) was confirmed by RT-qPCR (Supplementary Figure 1a-c) and Western blot (Supplementary Figure 1d) showing a reduction of Lim1 expression raising up to $90 \%$ at all time points tested, ranging from $24 \mathrm{~h}$ to 96 or $120 \mathrm{~h}$, in all 3 cell lines. Transient transfection with siCtl $(50 \mathrm{nM})$ did not alter Lim1 expression. Similar results were obtained with the two other sets of siRNAs (data not shown). These results indicated specificity and efficiency of Lim1 silencing.

Cell motility was assessed by wound healing assay. The transient transfection with siLhx1 decreased ACHN cell motility by around $60 \%$ at $12 \mathrm{~h}$ or $24 \mathrm{~h}$ post-transfection (Figure 1a). Similar results were obtained in Caki2 (50\%) cells (Figure 1b) and A498 (40\%) cells (Figure 1c). Cell migration and invasion were analyzed using transwell assays and inhibited at $24 \mathrm{~h}$ or 48h post-transfection with siLhx1 respectively by $50 \%$ and $40 \%$ in ACHN cells (Figure 2a,d), by $50 \%$ and $60 \%$ in Caki2 cells (Figure 2b,e) and by $50 \%$ and $60 \%$ in A498 cells (Figure 2c,f). Similar results were obtained with the two other sets of siRNAs (data not shown). In 
another set of experiments, we also assessed cell motility, migration and invasion in 786-0 cells either untransfected or transfected with wild-type VHL, truncated $\Delta \mathrm{VHL}$, or vector alone. We did not observe any difference in the effects of siLhx 1 depending on the VHL status of the cells (Supplementary Figures 2-4). Thus, Lim1 silencing decreased cell movements in all cell lines tested and regardless of the VHL statut.

Lim1 is involved in the expression of various proteins regulating cell movements and EMT

The above results prompted us to investigate the molecular mecanisms regulated by Lim1 to control the cell movement process. We analyzed the expression of markers associated with invasiveness and EMT in all 3 cell lines (Figure 3, Supplementary Figures 5 and 6, and Supplementary Table 1). Lim1 expression was knockdown for 24 to $96 \mathrm{~h}$ and many targets were dys-regulated in a time-dependent manner, with an expression profile quite similar from one cell line to another. Lim1 targets include: MMPs (1/2/3/8/9), proteins involved in EMT (snail1, Twist1/2) or cell adherence (fibronectin, paxillin, FAK), and proteins known as prometastatic (CXCR4, SDF-1, ANG-1). Similar results were obtained with the two other sets of siRNAs (data not shown). These results strongly suggest that Lim1 is involved in cell movements and regulates a large panel of proteins involved in invasiveness and EMT to achieve these effects. Clearly, these results argument the pro-metastastic potential of Lim1.

\section{Lim1 induces clonogenicity in human CCC cells}

We also performed colony forming assays to assess an other property required for the development of distant metastasis, i.e. clonogenicity. This assay provides a straightforward method to assess the transforming potential of an oncogene. Our experiments revealed that 
Lim1 knockdown with siLhx 1 significantly reduced colony formation by up to $60 \%, 85 \%$ and $70 \%$ in ACHN, Caki2 and A498, respectively (Figures 4a-c). Clonogenecity was also assessed in 786-0 cells either untransfected or transfected with wild-type VHL, truncated $\Delta \mathrm{VHL}$, or vector alone and shown to be not affected by the VHL status of the cells (Supplementary Figure 7). In addition to the results presented above on cell movements, these experiments strengthen the potential pro-metastatic activity of Lim1 in human CCC regardless of VHL status

\section{Lim1 is constitutively expressed in metastatic CCC tissues}

We have previously shown that Lim1 is constitutively reexpressed in tumor tissues based on the analysis of 44 tumoral/normal corresponding CCC tissue pairs independently on tumor stage and grade. ${ }^{7}$ Here, we investigated matched primary and metastatic tissue pairs for Lim1 expression either by Western blot when fresh or frozen tissues were available or by immunohistochemistry when tissues were only available in paraffin blocks. Western blot analysis showed Lim1 expression in the 4 primary samples and in the 6 metastatic samples available (Figure 5a). IHC staining showed that Lim1 was expressed in 18/19 primary samples and in 24/26 metastatic samples (Figure 5b,c). For the primitive CCC samples, the Hscore was distributed from 0 to 170 and for the metastasis from 0 to 240 . The staining was variable within the different tumoral areas in a same tumor, both in primary tumor tissues and metastases (Figure 5b-d). The comparison of H-score between primitive and metastatic tissue was possible in only 17 patients who had the primary tumor and the corresponding metastatic tissue, and we found a higher expression of Lim1 in metastatic tissues compared to matched primary tumor tissues in $15 / 17$ patients. The H-score average of all metastatic samples was significantly higher $(P$ value $=0.009)$ than that of all primary tumors (Figue 5e). Only four

cases of tumor tissues harboring sarcomatoid components were available that did not allow to 
assess a possible link between Lim1 staining and sarcomatoid tumor cells. As we have shown in the previous work, ${ }^{7}$ no correlation was found between the H-score level and the tumor stage in the primary tissues. Interestingly the H-score in metastatic tissues was correlated with the disease stage $(P$ value $=0.04)$ (Figure $5 f)$. Theses results confirm again the implication of Lim1 in metastases developpement.

\section{Lim1 is part of the machinery leading to metastasis development}

We next investigated the effects of Lim1 on metastasis development in vivo. Caki2 or 786-0 cells in which Lim1 was knockdown with siLhx1 (In Vivo Ready siRNA targeting exon 2) were injected intraveinously into the lateral tail vein of Balb/c nude mice. We choose to use this siRNA wich is more stable than the siRNA standard to ensure a long-lasting inhibition of Lim1 expression. Lim1 expression was analysed from cell suspensions used for mice injection and RT-qPCR analysis shows Lim1 inhibition by more than $90 \%$ with siLhx1 in both cell lines (Figure 6a).

After 3 weeks, all mice were euthanized, and lungs were collected from each mouse. Macroscopic view and histologic analysis were conducted to assess the presence of metastasis. Through qualitative and quantitative analysis, there was a meaningful reduction in number and size of pulmonary micro-metastases in mice implanted with Lim1-depleted Caki2 or 786-0 cells (Figure $6 \mathrm{~b}$ and $6 \mathrm{c}$ ) compared to the corresponding controls. There were between 3 to 6 and 1 to 6 pulmonary nodules in mice receiving untransfected and siCtltransfected Caki2 and 786-0 cells, respectively, while, remarkably, the number of nodules found in the lungs of mice receiving siLhx1-transfected cells were between 0 and 1 for Caki2 cells, and no nodules were detected for 786-0 cells. A representative nodule is also depicted (Figure 6d). Therefore, the in vivo studies demonstrate that Lim1 stimulates the metastatic 
properties of $\mathrm{CCC}$ cells. Thus, targeting Lim1 may have great therapeutic potential for treating human $\mathrm{CCC}$. 


\section{DISCUSSION}

Cancer metastasis is a multistep process in which malignant cells escape from the primary tumor to colonize distant, secondary sites. ${ }^{27}$ At metastatic stages, human CCC remains largely uncurable. The genetic changes and the biological mechanisms that drive RCC metastasis are relatively unknown.

The hypothesis we have from our studies and from the investigations of other groups is that tumors hijack developmental signaling pathways and markers, for their own growth. During renal tumorigenesis, Pax1/2 (paired box gene 2), Lim1, and WT1 (Wilms tumor protein) transcription factors, and the $\mathrm{SHH}$, Notch and Wnt (Wingless integrated) signaling pathways are reactivated. ${ }^{28}$ It has been shown that the blockade of the SHH-Gli signaling pathway induces cancer cell death. In addition, recent evidence suggests that a SHH paracrine mechanism mediating tumor-mesenchymal interactions may lead to metastasis. ${ }^{29}$ Targeting the SHH-Gli pathway has shown promising in vivo results on tumor growth in gastric, pancreatic, prostatic and breast cancers and medulloblastoma. ${ }^{30}$ We previously demonstrated that the SHH pathway is specifically re-expressed in human $\mathrm{CCC}$ and that its targeting results in tumor growth inhibition by inhibiting tumor cells proliferation and inducing apoptosis. ${ }^{5}$ In this previous study, we also showed that the SHH-Gli signaling pathway interacts with various oncogenic and developmental pathways including the PI3K/Akt, the NF-kB (nuclear factor-kappa B), and the MAPK (mitogen-activated protein kinases) pathways which have been shown to be critical for CCC. ${ }^{6,31}$ These results are reminiscent of what is observed during kidney development.

Importantly, we identified Lim1 as a Gli target in this disease. LIM homeobox genes are an important subfamily of homeobox genes which encode LIM-homeodomain proteins featuring two LIM domains in their amino termini and a centrally located homeodomain allowing 
interactions with specific DNA elements in target genes. Among 12 human LIM homeobox genes, 10 LIM-homeodomain proteins have been reported to be associated with cancer, including Lim1. Thus, besides its primordial roles during development, it has been reported that Lim1 is reactivated or overexpressed in some cancer types. ${ }^{17-19}$ No reports went deeper into its possible involvement in their pathogenicity and metastatic spread except studies in medulloblastoma. ${ }^{21}$ We identified Lim1 as a new oncogene in human CCC, regulating cell proliferation and apotosis. Additionnally, preliminary results suggested that Lim1 blockade induced substantial inhibition of cell movements.

Here we extent our previous results showing that Lim1 is involved in cell motility, migration and invasion in vitro in 3 additional cell lines, i.e. ACHN, Caki2 and A498 cells. Furthermore, through Lim1 depletion experiments we also show that Lim1 regulates clonogenicity of our panel of human CCC cell lines in vitro. All these effects were independent on VHL status as they were observed in cells expressing of not VHL, a nd clearly demonstrated in 786-0 cells either untransfected or transfected with VHL constructs. Various proteins belonging to the invasion machinery and EMT were shown to be regulated by Lim1. Interestingly, the profile of proteins regulated by Lim1 from one cell line to another, although very similar, also showed some cell specificities. We expected such results since these cell lines were derived from the tumor of different patients, and because it is now approved that CCC tumors are heterogeneous from patient to patient and in a single tumor at genetic and molecular levels. ${ }^{32}$ Clearly, such a result adds some levels of difficulties in the search of active therapies for human CCC. The fact that Lim1 depletion inhibits tumor cell movements of all cell lines tested using similar and probably different molecular pathways argue for a more widespread application of Lim1 targeting for therapeutic intervention in this pathology. In addition, these observations pave the way for additional fields of investigation in the search of the molecular mechanisms accounting for metastasis development in human CCC. For 
example, the observation that Lim1 silencing is associated with TIMP-1/MMPs inhibition simultaneously, surprised us initially, however, this unexpected balance between TIMP1/MMPs has been found in several cancers. Moreover a high level expression of TIMP-1 is correlated with a poor prognosis in RCC. This observation demonstrates the complexity of the mechanisms involved in carcinogenesis. ${ }^{33,34}$ The observations that Lim1 is expressed in all CCC metastases tested and the available corresponding primary tumors with an higher level in metastasis compared to the primary tumors ( $P$ value 0.009$)$, and that the level of Lim1 expression in metastases was correlated with tumor stage argument further its role in metastasis development. Tumors containing sarcomatoid components have the worse prognostic with an expected life expectancy of one year, vs. 40 months for patients with tumor with no sarcomatoid components. The cohort we used did not allow us to assess whether Lim1 is part of the molecular signature of sarcomatoid areas in human CCC.

Lim1 involvement in metastasis development in vivo environment was clearly demonstrated in the in vivo metastatic model used in the present study. This is a well-known model to directly assess quantitatively and qualitatively the development of metastasis, and it has been used with success for human CCC as well. ${ }^{35}$ In addition, it is suitable to assess the role of potential therapeutic targets against which there are no chemical inhibitors available yet. We show here that the metastatic phenotype of human CCC is regulated, at least in part, by Lim1 expression. Compared with the respective controls, considering metastasis number and size, mice receiving cells expressing siLhx1 developed significantly less lung metastasis.

Thus, we can add Lim1 to the short list of metastasis-promoting markers shown to be involved in metastasis development in human CCC. Among the recently identified markers we can cite SOX4, acting through the induction of EMT, ${ }^{36}$ the complement component $1 \mathrm{q}$ subcomponent binding protein (C1QBP), acting through the regulation of the GSK3 (Glycogen synthase kinase-3)/ $\beta$-catenin/L1CAM (L1 cell adhesion molecule) signaling 
pathway, ${ }^{37}$ caveolin-1, that could act also through the regulation of the $\beta$-catenin pathway, ${ }^{38}$ the miR-193a-3p, that directly targets PTEN, ${ }^{39}$ and the novel lncRNA termed metastatic renal cell carcinoma-associated transcript 1 (MRCCAT1), that acts via inhibiting NPR3 and activating p38-MAPK signaling. ${ }^{40}$ In addition, comparing early metastatic and non-metastatic CCC samples, it was also discovered that certain differentilally expressed genes including JUN, TNF, RHOB, NR4A1, TGFß2, LAMA1, LAMA2 and LAMA4 were potential target genes associated with early metastatic $\mathrm{CCC} .^{41}$ In contrast, CD82/KAI1, acts as a metastasis suppressor in human CCC through the TGF- $\beta 1 /$ Smad signaling, ${ }^{42}$ as it is the case for KLF6, shown paradoxically as promoting metastasis in other cancer types, that acts via the transcriptional repression of E2F $1{ }^{43}$ It is interesting to note that although these metastasispromoting markers have been demonstrated experimentally to be involved in metastatic spread in human CCC, they were not identified at risk loci in genome-wide or meta-analysis studies. ${ }^{44}$ In a recent report characterizing the long non-coding RNA transcriptome in CCC by next-generation deep sequencing, 4 clusters were identified, associated with distinct clinicopathological and genomic features of this disease. The cluster 4 was associated with tumor subtype arising from the distal tubules of the nephron. Lim1 was found to be overexpressed in this cluster compared to the others clusters, consistent with downregulation of its cis-acting lncRNAs RP11-283I3, and thus argumenting for a role for Lim1 in this kidney cancer subtype. Clearly, further studies will help to better characterize how Lim1, as well as other metastasis-promoting markers, act on metastasis development in this refractory disease, and using different but additional experimental approaches.

In summary, combining previous results on tumor growth ${ }^{7}$ with the ones obtained in the present studies, Lim1 possesses several characteristics that make it a highly promising potential therapeutic target for advanced CCC therapy. Lim1 stimulates tumor cell proliferation, migration, invasion, in vivo tumorigenesis and metastatic spread, and inhibits 
tumor cells apoptosis. In addition, the results reported here may open new gates towards the identification of additional targets with therapeutic potential and also highlight the heterogeneous nature of human CCC tumors. Indeed, depending on the cell line considered, Lim1 regulates different sets of invasive or EMT-inducing proteins, but leading to the same overall effects on cell movements and metastasis, adding complexity to the search of the mechanisms underlying metastatic spread in human $\mathrm{CCC}$, and thus to the definition of 'universal' tools to eradicate mestastasis. Further investigations are required to define how the interplay of these molecular pathways and markers lead ultimately to metastasis development. In total, we have shown that Lim1 expression maintains the invasive potential of human CCC tumor cells in vitro and in vivo, which plays a pivotal role in the malignant progression of this cancer type and thus carries highly potent therapeutic implications. In this context, we recently developed in collaboration with chemists a very efficient tool to inhibit Lim1 expression in tumors, using new and innovative polydiacetylenic nanofibers able to vehicle siRNA in vitro and in vivo. ${ }^{45}$ Next step will be to assess the efficiency of these tools in relevant models and ultimately to patients. 


\section{MATERIALS AND METHODS}

\section{Cell lines and cell culture}

The following human CCC cell lines were used: 786-0, A498, ACHN and Caki2. Cells were obtained from the American Type Culture Collection (Manassas, Virginia, USA). They were cultured in DMEM (Dulbecco's Modified Eagle Medium) supplemented with 10\% fetal bovine serum (FBS) and 1\% antibiotics (penicillin/streptomycin) (Thermo Fisher Scientific, Courtaboeuf, France) at $37^{\circ} \mathrm{C}$ in a humidified atmosphere of $10 \% \mathrm{CO}$. Clones of $786-0$ cells transfected either with human VHL gene (786-0 VHL, coding for native VHL 1-213), inactive truncated human VHL gene (786-0 $\Delta$ VHL, coding for VHL 1-115), or the vector alone only pCR3-Uni (786-0 V) were also used and selected using G418 (500 $\mu \mathrm{g} / \mathrm{ml})$, as previously detailed. $^{5}$

\section{Patients and clinical samples}

We analyzed a cohort of 22 patients with CCC metastases (Supplementary Table 2) that were obtained from the Urology Department of the 'Nouvel Hôpital Civil' (Pr. Hervé Lang, Strasbourg, France) or from the Biologic Resource Center (Strasbourg Hospital, France) via the Hemato-oncology Department of the Strasbourg University Hospital (Dr Philippe Barthélémy, Strasbourg, France) and the Pathology Department (Dr Véronique Lindner). Surgical total or partial nephrectomy were available for 20 patients, two of them had two tumors ( 22 tumors), with a men to women ratio 1.44 . They were between 40 and 86 years old (average age : 58,3) at the time of diagnosis. Informed consent was obtained from all patients and the study was approved by the French Human Ethics Committee. One to four paraffin blocks were selected depending of the homogeneity of the tumor. The repartition in the pTNM stage according to the $8^{\text {th }}$ edition of the $\mathrm{UICC}^{46}$ was: 
- 4 tumors in pT1a and $2 \mathrm{pT} 1 \mathrm{~b}$ stages (including the tumors from the 2 patients that relapsed)

- 2 patients in pT2a and $2 \mathrm{pT} 2 \mathrm{~b}$ stages

- 9 patients in pT3a stage

- 1 patient in stage $\mathrm{pT} 4$

For two patients, 1 at clinical stage cT3 and the other at cT4, only the tumoral tissue of the biopsy sample was available. Also, for two patients, we only had access to metastasis, and no data on the corresponding primary tumors. The primitive carcinomas showed a Fuhrman grade 2 to 4 . Among the tumors with grade 4, four were explained by a sarcomatoid component also identified in the corresponding metastasis.

These patients developed one or more lymph nodes, visceral or bone metastasis (less than one years to 12 years after the diagnosis of the primitive tumors) and for one patient, the diagnosis of the RCC was done on bone metastasis. In total, 30 metastasis were analyzed by immunohistochemistry and/or by Western blot depending on the availability of the tissues, paraffin-embedded or frozen, or both. Thus, for 14 patients, tissues were only conserved in formol, for 1 patients tissues were only conserved in liquid nitrogen, while for 7 patients tissues were available in formol and liquid nitrogen. Sites of metastases were lung, bone, lymph node, adrenal gland, parotid gland, bronchus, pleura, trachea, skin and liver.

\section{RNA isolation and quantitative real-time PCR analysis}

Total RNAs were extracted and reverse transcribed as previously described. ${ }^{47}$ cDNAs were amplified using the 'SsoAdvanced ${ }^{\mathrm{TM}}$ Universal SYBR ${ }^{\circledR}$ Green Supermix' kit (Biorad, Marnes-la-Coquette, France) in the CFX Connect ${ }^{\mathrm{TM}}$ Real-Time System (Biorad). Sense and antisense primers used were for Lim1 (primers designed by Biorad and provided as a mixture, 
PrimePCRT⿳ $\mathrm{SYBR}^{\circledR}$ Green Assay) and for cyclophilin A CCACCGCCGAGGAAAACCG (forward primer) and TGGACAAGATGCCAGGACCCGT (reverse primer), (Eurogentec, Angers, France).

\section{Western blot analysis}

Western blot assay was performed as previously detailed. ${ }^{46}$ The mouse monoclonal antihuman Lim1 antibody and the mouse monoclonal anti-human VHL antibody were purchased from Abcam (Paris, France) and used at 1/3000 and 1/500 dilutions, respectively. The mouse anti-human housekeeping GADPH was purchased from Sigma-Aldrich/Merck and used at 1/20000 dilution. The information on all other primary antibodies and dilutions used is listed in Supplementary Table 3. The appropriate horseradish peroxidase-conjugated secondary antibody was used. Immunoreactivity was visualized with the enhanced chemiluminescence immunoblotting detection kit Luminata ${ }^{\mathrm{TM}}$ (Merck Millipore, Molsheim, France).

\section{siRNA}

Three sets of Lim1 siRNAs were designed targeting different portions of the Lim1 mRNA corresponding to exon 1, 2 (LIM domains) and 3 (Homeodomain). All siRNA were obtained from Life technologies (Saint-Aubin, France). Transfections were performed using jetPRIME $^{\circledR}$ (Polyplus transfection, Ilkirch, France) according to the manufacturer's instructions. Briefly, tumor cells were seeded in 24- or 6-well plates or Petri dishes $100 \mathrm{~nm}$ (for in vivo study), grown for $24 \mathrm{~h}$ and transiently transfected for 24 to $120 \mathrm{~h}$ (depending on the experiment) with either Lim1 exon-1 targeting siRNA standard (siLhx1ex1), Lim1 exon-2 targeting siRNA standard (siLhx1ex2) or Lim1 exon-3 targeting siRNA standard (siLhx1ex3) or control siRNA standard ( $\mathrm{siCtl}$ ), as precised in the Figures or Figure legends. For the in vivo 
study cells were transfected with either Lim1 exon-2 targeting siRNA in vivo ready (siLhx1ex2) or control siRNA in vivo ready (siCtl) (Life technologies)

\section{Wound healing assay}

Wound healing assay was performed as exposed previously. ${ }^{7}$ Briefly, tumor cells were grown in 24-well plates to confluence and transiently transfected with siLhx1 or siCtl. After $24 \mathrm{~h}$ of treatment, the wound was created in the center of the cell monolayer with a sterile plastic scratcher. The ability of the cells to migrate into the wound area was assessed after $12 \mathrm{~h}$ and $24 \mathrm{~h}$ by comparing the 0 - 12 - and 24-h micrographs of several marked points along the wounded area. The percentage of recovered wound area was calculated by dividing the recovered area after $12 \mathrm{~h}$ or $24 \mathrm{~h}$ by the initial wound area at zero time.

\section{Cell migration and invasion assays}

Tumor cells were grown for $24 \mathrm{~h}$ and transiently transfected for 24 to $48 \mathrm{~h}$ with siLhx 1 or siCtl.The migration and invasion assays cells were performed on Boyden chamber as detailed. $^{7,46}$

\section{Colony formation assay}

Clonogenicity was assessed with a colony-forming assay. ${ }^{48}$ Cells were seeded in 6-well plates at $50 \%$ confluence and then transfected with siLhx 1 or siCtl at $50 \mathrm{nM}$ or untranfected. $24 \mathrm{~h}$ post-transfection, cells were seeded in 6-well plates at 300 cells/well and cultured for 15 days. Colonies on each plate were counted after fixation and coloration by crystal violet.

\section{Histology and immunohistochemistry analysis}


Tissues were fixed in 10\% neutral-buffered formalin and processed for histologic examination including embedding in paraffin, sectioning, and staining with hematoxylin and eosin. Four $\mu \mathrm{m}$ sections from selected paraffin blocks for each specimen were used for immunohistochemical analysis. This analysis was realized on a Ventana Roche Benchmark $\mathrm{XT}$ and with the same antigen retrieval process, in a EDTA citrate buffer $(\mathrm{pH} 8,3)$ during 30 min (mild cell conditioning, CC1, Ventana Roche Systems, AZ, USA), followed by incubation with Lim1 mouse monoclonal antibody (clone 2D3 monoclonal, Abcam) at 1/100 dilution during 32 minutes at $36^{\circ} \mathrm{C}$ and via the ultraView Universal DAB Detection Kit (Ventana Roche Systems).

Immunochemistry results was evaluated by an experienced pathologist and by a semiquantitative approach assigning an H-score (or "Histoscore") to tumor samples. The percentage of tumoral cells was determined for each different nuclear staining intensity $(0 /+/+/++/+++)$ and then, the sum of individual H-scores for each intensity level was done, using the following formula: $\mathrm{H}$ score $=1 \times(\%$ of cells with an intensity $1+)+2 \times(\%$ of cells with an intensity $2+)+3 \times(\%$ of cells with an intensity $3+)$.

\section{Human CCC lung metastatis assay}

For in vivo lung metastasis experiments, 1 x $10^{6}$ of 786-0 or Caki2 cells were intravenously injected into the lateral tail vein of 6-week old female Balb/c nude mice (Charles River Laboratories, L'Arbresle, France). Experimets were approved by the French Human Ethics Committee Mice. were randomly divided into 3 groups ( 5 mice per group) for each set of experiments with each cell line. One group was inoculated with untransfected control cells, a second group with cells that were transfected with siLhx1, 24h prior to injection and the third group with cells transfected with siCtl $24 \mathrm{~h}$ prior to injection. The mice were euthanized 3

weeks after cell injection, lung were harvested and then processed for paraffin-embedded 
$4 \mu \mathrm{m}$ sections (5 levels). These sections were stained with hematoxylin and eosin to confirm the presence of metastasic tumors. Metastasis were analyzed qualitatively and quantitatively by an experienced pathologist. The study was approved by the French Human Ethics Committee

\section{Statistical analysis}

All values are expressed as mean \pm s.e.m. Statistical analysis was performed when appropriate using Student's $t$ test, one-way or two-way ANOVA followed by the Student-Newman-Keul's test for multiple comparisons. A $P<0.05$ was considered statistically significant. ('*' represents $\mathrm{P}<0.05,^{\text {‘**’ }}$ represents $\mathrm{P}<0.01$, '***’ represents $\mathrm{P}<0.001$ ). 


\section{CONFLICT OF INTEREST}

The authors declare no onflict of interest.

\section{ACKNOWLEDGMENTS}

This study was sponsored by INSERM (recipient TM), the University of Strasbourg (recipient TM) and the Ligue Contre le Cancer (recipient TM). The authors thank Martine MUCKENSTURM, Fabienne REYMANN and Angélique WERCK, from the Department of

Pathology, University Hospital, Strasbourg, for their technical assistance in immunohistochemistry. 


\section{REFERENCES}

1 Ferlay J, Soerjomataram I, Dikshit R, Eser S, Mathers C, Rebelo M et al. Cancer incidence and mortality worldwide: sources, methods and major patterns in GLOBOCAN 2012. Int J Cancer 2015; 136: E359-386.

2 Escudier B, Porta C, Bono P, Powles T, Eisen T, Sternberg CN, Gschwend JE, De Giorgi U, Parikh O, Hawkins R, Sevin E, Négrier S, Khan S et al. Randomized, controlled, double-blind, cross-over trial assessing treatment preference for pazopanib versus sunitinib in patients with metastatic renal cell carcinoma: PISCES Study. J Clin Oncol 2014; 32: 1412-1418.

3 Posadas EM, Limvorasak S, Figlin RA. Targeted therapies for renal cell carcinoma. Nat Rev Nephrol 2017; 13: 496-511.

4 Mehta K, Patel K, Parikh RA. Immunotherapy in genitourinary malignancies. J Hematol Oncol 2017; Apr 24;10(1):95. doi: 10.1186/s13045-017-0457-4.

5 Dormoy V, Danilin S, Lindner V, Thomas L, Rothhut S, Coquard C et al. The sonic hedgehog signaling pathway is reactivated in human renal cell carcinoma and plays orchestral role in tumor growth. Mol Cancer 2009: 8: 123.

6 Sourbier C, Lindner V, Lang H, Agouni A, Schordan E, Danilin S et al. The phosphoinositide 3-kinase/Akt pathway: a new target in human renal cell carcinoma therapy. Cancer Res 2006; 66: 5130-5142.

7 Dormoy V, Béraud C, Lindner V, Thomas L, Coquard C, Barthelmebs M et al. LIMclass homeobox gene Lim1, a novel oncogene in human renal cell carcinoma. Oncogene 2011; 30: 1753-1763. 
8 Barnes JD, Crosby JL, Jones CM, Wright CV, Hogan BL. Embryonic expression of Lim-1, the mouse homolog of Xenopus Xlim-1, suggests a role in lateral mesoderm differentiation and neurogenesis. Dev Biol 1994; 161: 168-178.

9 Hukriede NA, Tsang TE, Habas R, Khoo PL, Steiner K, Weeks DL et al. Conserved requirement of Lim1 function for cell movements during gastrulation. Dev Cell 2003; 4: 83-94.

10 Cheah SS, Kwan KM, Behringer RR. Requirement of LIM domains for LIM1 function in mouse head development. Genesis 2000; 27: 12-21.

11 Zhao Y, Kwan KM, Mailloux CM, Lee WK, Grinberg A, Wurst W et al. LIMhomeodomain proteins Lhx1 and Lhx5, and their cofactor Ldb1, control Purkinje cell differentiation in the developing cerebellum. Proc Natl Acad Sci USA 2007; 104: $13182-13186$.

12 Ledig S, Brucker S, Barresi G, Schomburg J, Rall K, Wieacker P. Frame shift mutation of LHX1 is associated with Mayer-Rokitansky-Kuster-Hauser (MRKH) syndrome. Hum Reprod 2012; 27: 2872-2875.

13 Huang CC, Orvis GD, Kwan KM, Behringer RR. Lhx1 is required in Müllerian duct epithelium for uterine development. Dev Biol 2014; 389: 124-136.

14 Cirio MC, Hui Z, Haldin CE, Cosentino CC, Stuckenholz C, Chen X et al. Lhx1 is required for specification of the renal progenitor cell field. PLoS One 2011; 6: e18858.

15 Costello I, Nowotschin S, Sun X, Mould AW, Hadjantonakis AK, Bikoff EK et al. Lhx1 functions together with Otx2, Foxa2, and Ldb1 to govern anterior mesendoderm, node, and midline development. Genes Dev 2015; 29: 2108-2122.

16 Ye L, Evans J, Gargett CE. Lim1/LIM1 is expressed in developing and adult mouse and human endometrium. Histochem Cell Biol 2012; 137: 527-536. 
17 Varis A, Wolf M, Monni O, Vakkari ML, Kokkola A, Moskaluk C et al. Targets of gene amplification and overexpression at 17q in gastric cancer. Cancer Res 2002; 62: $2625-2629$.

18 Sato N, Fukushima N, Maitra A, Matsubayashi H, Yeo CJ, Cameron J et al. Discovery of novel targets for aberrant methylation in pancreatic carcinoma using highthroughput microarrays. Cancer Res 2003; 63: 3735-3742.

19 Tong WG, Wierda WG, Lin E, Kuang SQ, Bekele BN, Estrov Z et al. Genome-wide DNA methylation profiling of chronic lymphocytic leukemia allows identification of epigenetically repressed molecular pathways with clinical impact. Epigenetics 2010; 5: 499-508.

20 Guertl B, Senanayake U, Nusshold E, Leuschner I, Mannweiler S, Ebner B et al. Lim1, an embryonal transcription factor, is absent in multicystic renal dysplasia, but reactivated in nephroblastomas. Pathobiology 2011; 78: 210-219.

21 Mumert M, Dubuc A, Wu X, Northcott PA, Chin SS, Pedone CA et al. Functional genomics identifies drivers of medulloblastoma dissemination. Cancer Res 2012; 72: 4944-4953.

22 Qu LS, Jin F, Guo YM, Liu TT, Xue RY, Huang XW et al. Nine susceptibility loci for hepatitis B virus-related hepatocellular carcinoma identified by a pilot two-stage genome-wide association study. Oncol Lett 2016; 11: 624-632.

23 Mikami S, Oya M, Mizuno R, Kosaka T, Ishida M, Kuroda N et al. Recent advances in renal cell carcinoma from a pathological point of view. Pathol Int 2016; 66: 481490.

24 Lin TC, Liu YP, Chan YC, Su CY, Lin YF, Hsu SL et al. Ghrelin promotes renal cell carcinoma metastasis via Snail activation and is associated with poor prognosis. $J$ Pathol 2015; 237: 50-61. 
25 Lin YW, Lee LM, Lee WJ, Chu CY, Tan P, Yang YC et al. Melatonin inhibits MMP-9 transactivation and renal cell carcinoma metastasis by suppressing Akt-MAPKs pathway and NF-кB DNA-binding activity. J Pineal Res 2016; 60: 277-290.

26 Zhao Z, Liu H, Hou J, Li T, Du X, Zhao X et al. Tumor Protein D52 (TPD52) Inhibits Growth and Metastasis in Renal Cell Carcinoma Cells Through the PI3K/Akt Signaling Pathway. Oncol Res 2017; 25:773-779..

27 Valastyan S, Weinberg RA. Tumor metastasis: molecular insights and evolving paradigms. Cell 2011; 147: 275-292.

28 Dormoy V, Jacqmin D, Lang H, Massfelder T. From development to cancer: lessons from the kidney to uncover new therapeutic targets. Anticancer Res 2012; 32:36093617.

29 Li H, Yue D, Jin JQ, Woodard GA, Tolani B, Luh TM, et al. Gli promotes epithelialmesenchymal transition in human lung adenocarcinomas. Oncotarget 2016; 7:8041580425.

30 Stanton BZ, Peng LF. Small-molecule modulators of the Sonic Hedgehog signaling pathway. Mol Biosyst 2010; 6: 44-54.

31 Sourbier C, Danilin S, Lindner V, Steger J, Rothhut S, Meyer N et al. Targeting the nuclear factor-kappaB rescue pathway has promising future in human renal cell carcinoma therapy. Cancer Res 2007; 67: 11668-11676.

32 Beksac AT, Paulucci DJ, Blum KA, Yadav SS, Sfakianos JP, Badani KK. Heterogeneity in renal cell carcinoma. Urol Oncol 2017; pii: S1078-1439: 3021630218.

33 Xia Y, Yeddula N, Leblanc M, Ke E, Zhang Y, Oldfield E et al. Reduced cell proliferation by IKK2 depletion in a mouse lung-cancer model. Nat Cell Biol 2012; 14: 257-265. 
34 Kallakury BV, Karikehalli S, Haholu A, Sheehan CE, Azumi N, Ross JS. Increased expression of matrix metalloproteinases 2 and 9 and tissue inhibitors of metalloproteinases 1 and 2 correlate with poor prognostic variables in renal cell carcinoma. Clin Cancer Res 2001;7:3113-3119.

35 Jeong DE, Song HJ, Lim S, Lee SJ, Lim JE, Nam DH et al. Repurposing the antimalarial drug artesunate as a novel therapeutic agent for metastatic renal cell carcinoma due to its attenuation of tumor growth, metastasis, and angiogenesis. Oncotarget 2015; 6: 33046-33064.

36 Ruan H, Yang H, Wei H, Xiao W, Lou N, Qiu B et al. Overexpression of SOX4 promotes cell migration and invasion of renal cell carcinoma by inducing epithelialmesenchymal transition. Int J Oncol 2017; 51: 336-346.

37 Wang Y, Fu D, Su J, Chen Y, Qi C, Sun Y et al. C1QBP suppresses cell adhesion and metastasis of renal carcinoma cells. Sci Rep 2017; 7: 999.

38 Yerokhin VA, Shabaev VM. Nuclear Recoil Effect in the Lamb Shift of Light Hydrogenlike Atoms. Phys Rev Lett 2015; 115: 233002.

39 Liu L, Li Y, Liu S, Duan Q, Chen L, Wu T et al. Downregulation of miR-193a-3p inhibits cell growth and migration in renal cell carcinoma by targeting PTEN. Tumour Biol 2017; 39: 1010428317711951.

40 Li JK, Chen C, Liu JY, Shi JZ, Liu SP, Liu B et al. Long noncoding RNA MRCCAT1 promotes metastasis of clear cell renal cell carcinoma via inhibiting NPR3 and activating p38-MAPK signaling. Mol Cancer 2017; 16: 111.

41 Yang $\mathrm{H}$, Huo P, Hu G, Wei B, Kong D, Li H. Identification of gene markers associated with metastasis in clear cell renal cell carcinoma. Oncol Lett 2017; 13: $4755-4761$. 
42 Zhu J, Liang $\mathrm{C}$, Hua Y, Miao C, Zhang J, Xu A et al. The metastasis suppressor CD82/KAI1 regulates cell migration and invasion via inhibiting TGF- $\beta$ 1/Smad signaling in renal cell carcinoma. Oncotarget 2017; May 23. doi: 10.18632/oncotarget.18086.

43 Gao Y, Li H, Ma X, Fan Y, Ni D, Zhang Y et al. KLF6 Suppresses Metastasis of Clear Cell Renal Cell Carcinoma via Transcriptional Repression of E2F1. Cancer Res 2017; 77: $330-342$.

44 Scelo G, Purdue MP, Brown KM, Johansson M, Wang Z, Eckel-Passow JE et al. Genome-wide association study identifies multiple risk loci for renal cell carcinoma. Nat Commun 2017; 8: 15724.

45 Neuberg P, Hamaidi I, Danilin S, Ripoll M, Lindner V, Nothisen M, Wagner A, Kichler A, Massfelder T, Remy JS. Polydiacetylenic nanofibers as new siRNA vehicles for in vitro and in vivo delivery. Nanoscale 2018; 10:1587-1590.

46 Delahunt B, Egevad L, Samaratunga H, Varma M, Verrill C, Cheville J et al. UICC drops the ball in the 8th edition TNM staging of urological cancers. Histopathology 2017; 71: 5-11.

47 Béraud C, Dormoy V, Danilin S, Lindner V, Béthry A, Hochane M et al. Targeting FAK scaffold functions inhibits human renal cell carcinoma growth. Int J Cancer 2015; 137: 1549-1559.

48 Franken NA, Rodermond HM, Stap J, Haveman J, van Bree C. Clonogenic assay of cells in vitro. Nat Protoc 2006; 1: 2315-2319. 


\section{FIGURE LEGENDS}

Figure 1. Lim1 depletion inhibits cell motility in human CCC in vitro. Cells were transiently transfected with either siLhx1ex2 (siLhx1) or control siRNA (siCtl), both at $50 \mathrm{nM}$, or not transfected $(\mathrm{Ctl})$. Cell motility was then quantitatively analyzed and expressed in percentage of the cell surface in the wound area as a function of the time after the scratch, that is, 12 and 24 h. (a) Quantification of the effect of Lim1 depletion on ACHN cell motility (left panel). Representative pictures of the wound area at 0,12 and $24 \mathrm{~h}$ after the scratch (right panel). Scale bars correspond to $50 \mu \mathrm{m}$. (b) Quantification of the effect of Lim1 depletion on Caki2 cell motility. (c) Quantification of the effect of Lim1 depletion on A498 cell motility. Results are shown as mean \pm s.e.m., $\mathrm{n}=4$ in triplicata; $* * * P<0.001$ from corresponding siCtl.

Figure 2. Lim1 silencing decreases human CCC cell migration and invasion in vitro. Cells were transiently transfected with either siLhx1ex2 (siLhx1) or control siRNA (siCtl) both at $50 \mathrm{nM}$, or not transfected $(\mathrm{Ctl})$. Cell migration was analyzed at 24 and $48 \mathrm{~h}$ post-transfection using transwell inserts as detailed in Materials and Methods (a) in ACHN cells, (b) in Caki2 cells and (c) in A498 cells. Cell invasion was then analyzed at 24 and $48 \mathrm{~h}$ post-transfection using Matrigel-coated transwell inserts as detailed in Materials and Methods (d) in ACHN cells, (e) in Caki2 cells and (f) in A498 cells. Results are shown as mean \pm s.e.m., $\mathrm{n}=4$ in triplicata; $* P<0.05 ; * * P<0.01 ; * * * P<0.001$ from corresponding siCtl.

Figure 3. Lim1 regulates a large panel of proteins involved in cell movements. ACHN cells were transiently transfected with siLhx2ex1 (siLhx1) at $50 \mathrm{nM}$ for 48 to $120 \mathrm{~h}$, and the expression of various (a) metalloproteinases and TIMP-1, and proteins known to be involved in (b) EMT and (c) cell adherence or (d) proteins known as acting as pro-metastatic factors, was analyzed by Western blot. Anti-GAPDH antibody was used for visualization of protein gel loading. Representative gels from at least 3 experiments are depicted in the Figure. 
Figure 4. Lim1 silencing decreases human CCC cell clonogenicity. Cells were transiently transfected with either siLhx1ex2 (siLhx1) or control siRNA (siCtl), both at $50 \mathrm{nM}$, or not transfected (Ctl). Clonogenicity was assessed 15 days post-transfection by counting cell colonies as detailed in Materials and Methods. (a) Quantification of the effect of Lim1 depletion on the number of ACHN cell colonies (left panel). Representative pictures of the colonies in plates after cell coloration as detailed in Materials and Methods (Right panel) (b) Quantification of the effect of Lim1 depletion on the number of Caki2 cell colonies. (c) Quantification of the effect of Lim1 depletion on the number of A498 cell colonies. Results are shown as mean \pm s.e.m., $\mathrm{n}=4$ in triplicata; $* * P<0.01 ; * * * P<0.001$ from corresponding siCtl.

Figure 5. Lim1 is expressed in CCC metastasic and primary tissues with higher level of expression in metastasis. (a) Lim1 expression was analyzed in tumoral tissues of 6 patients, in both primary tumor tissues and corresponding metastasis for 4 patients and in metastatic tissues for 2 patients, depending on tissues availability as explained in Materials and Methods. Representative gels from at least 3 experiments are depicted in the Figure. Madr: Metastasis, adrenal; Mln, Metastasis, lymph node (b) For patient RCC12, Lim1 expression was analyzed by immunohistochemistry in primary tumor (upper images) and corresponding lung metastasis (lower images) at two magnifications. Lim1 H-score was 7.5 in primary tumor tissue and 130 in the metastasis. Scale bars correspond to $50 \mu \mathrm{m}$ for the lower magnifications (left images) and $20 \mu \mathrm{m}$ for the higher magifications (right images). (c) Lim1 expression analysis by immunohistochemistry in RCC16 patient's primary tumor (upper images) and corresponding skin metastasis (lower images) at two magnifications. Lim1 H-score was 22.5 in primary tumor tissue and 240 in the metastasis. Scale bars correspond to $50 \mu \mathrm{m}$ for the lower magnifications (left images) and $20 \mu \mathrm{m}$ for the higher magifications (right images). (d) 
Quantitative analysis of Lim1 staining according to H-score in primary and metastatic tissues depending on availabilities of the tissues (RCC5 only metastatic tissues were available). Results are shown as mean \pm s.e.m. when multiple primary sites were available for the same patients or multiple metastasis for a single primary tumor. (e) Average results from d corresponding to the H-score in primary tumors versus the H-score in metastasis and shown as mean \pm s.e.m., ${ }^{*} \mathrm{P}<0.01$ from primary tumors. (f). H-score in $\mathrm{pT} 1+2$ stages vs. $\mathrm{H}-\mathrm{Score}$ in pT3 +4 stages in prmary tumors (left panel). H-score in metastasis developed from primary tumors at $\mathrm{pT} 1+2$ stages vs. $\mathrm{H}$-score in metastasis developed from primary tumors at $\mathrm{pT} 3+4$ stages (right panel). Data are shown as mean \pm s.e.m., ${ }^{*} \mathrm{P}<0.05$ from $\mathrm{pT} 1+2$. Same sacle were used for both histograms.

Figure 6. Lim1 silencing reduces the development of pulmonary micro-metastatic nodules in vivo. Human Caki2 or 786-0 cells were transiently transfected with either siLhx1ex2 (siLhx1, in vivo ready) or siCtl ( $\mathrm{siCtl}$ in vivo ready ), both at $50 \mathrm{nM}$, or not transfected (Ctl) $24 \mathrm{~h}$ prior the injection. 1 million of cells were injected i.v in the tail vein of BalB/c nude mice and 3 weeks later, mice were euthanized, and lungs were harvested and analyzed for the presence of metastases. (a). Efficiency of Lim1 silencing in Caki2 and 786-0 cells that were injected in mice. (b). Comparison of numbers of pulmonary micro-metastatic nodules in mice receiving untransfected Caki2 cells and in mice receiving Caki2 cells transfected with siCtl $(\mathrm{Ctl}+\mathrm{siCtl}$, $\mathrm{n}=9$ and in mice receiving Caki2 cells transfected with siLhx1 (siLhx1, $n=4)$, as expressed as percent from $\mathrm{Ctl}+$ siCtl (Left panel). The diameters of each nodule was measured and expressed on average per mouse and then on average per group ( $\mu \mathrm{m})$ (Right panel). (c). Comparison of numbers of pulmonary micro-metastatic nodules in mice receiving untransfected 786-0 cells and in mice receiving 786- 0 cells transfected with siCtl $(\mathrm{Ctl}+\mathrm{siCtl}$, $\mathrm{n}=3$ ) and in mice receiving 786-0 cells tranfected with siLhx1 (siLhx1, $\mathrm{n}=4)$, as expressed 
as percent from $\mathrm{Ctl}+\operatorname{siCtl}($ Left panel). As for Caki2 experiments, the diameters of-each nodules were measured and expressed on average per mouse and then on average per group $(\mu \mathrm{m})$ (Right panel). Results are shown as mean \pm s.e.m. ${ }^{*} P<0.05 ; * * P<0.01 ; * * * P<0.001$ from corresponding $\mathrm{Ctl}+$ siCtl. (d). Representative pictures of a pulmonary micro-metastatic nodules. The arrow shown points to micro-metastatic nodule in lung. Scale bars correspond to $500 \mu \mathrm{m}$ for the lower magnifications (left image) and $50 \mu \mathrm{m}$ for the higher magifications (Right image). 
Figure 1

a
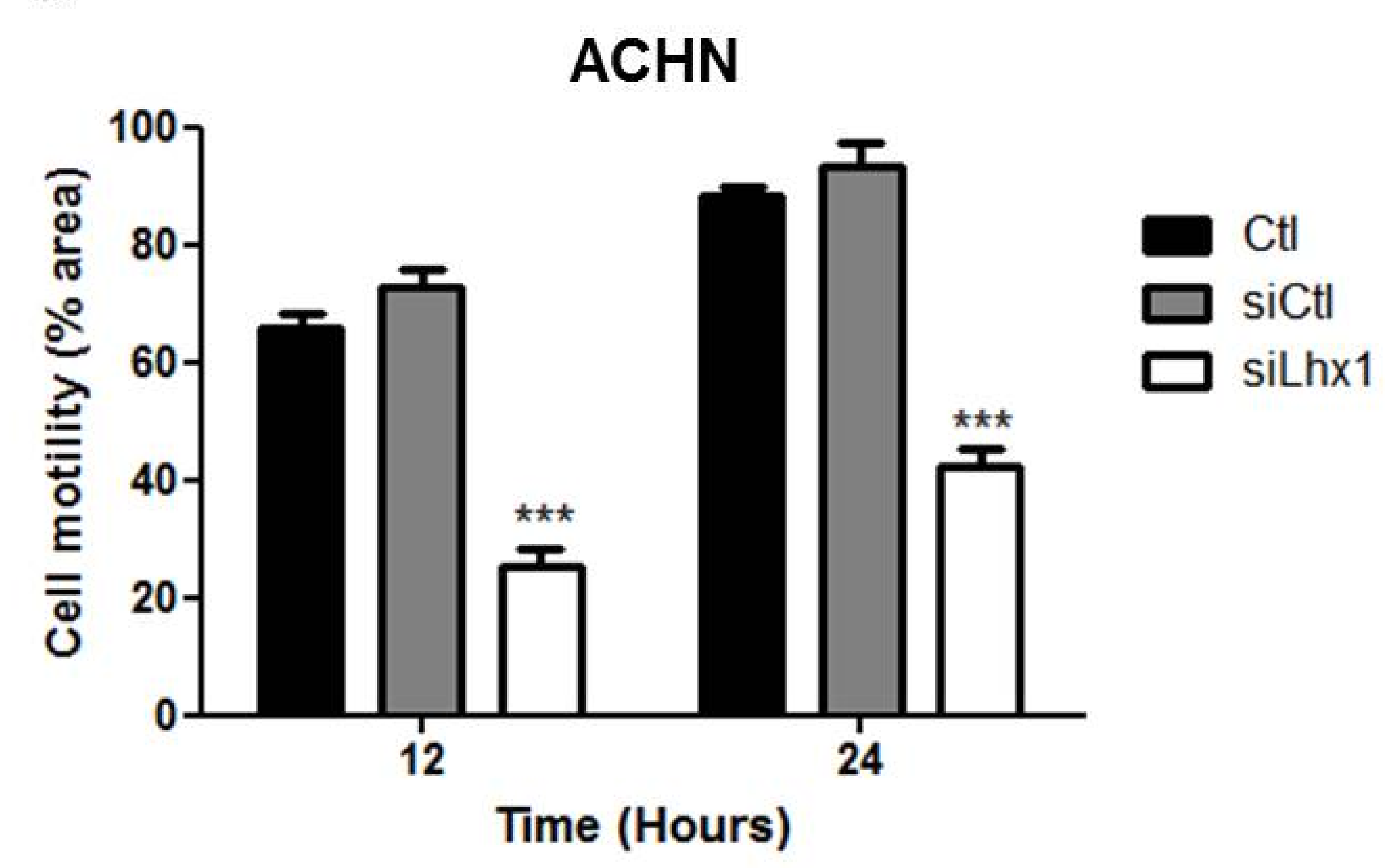

b

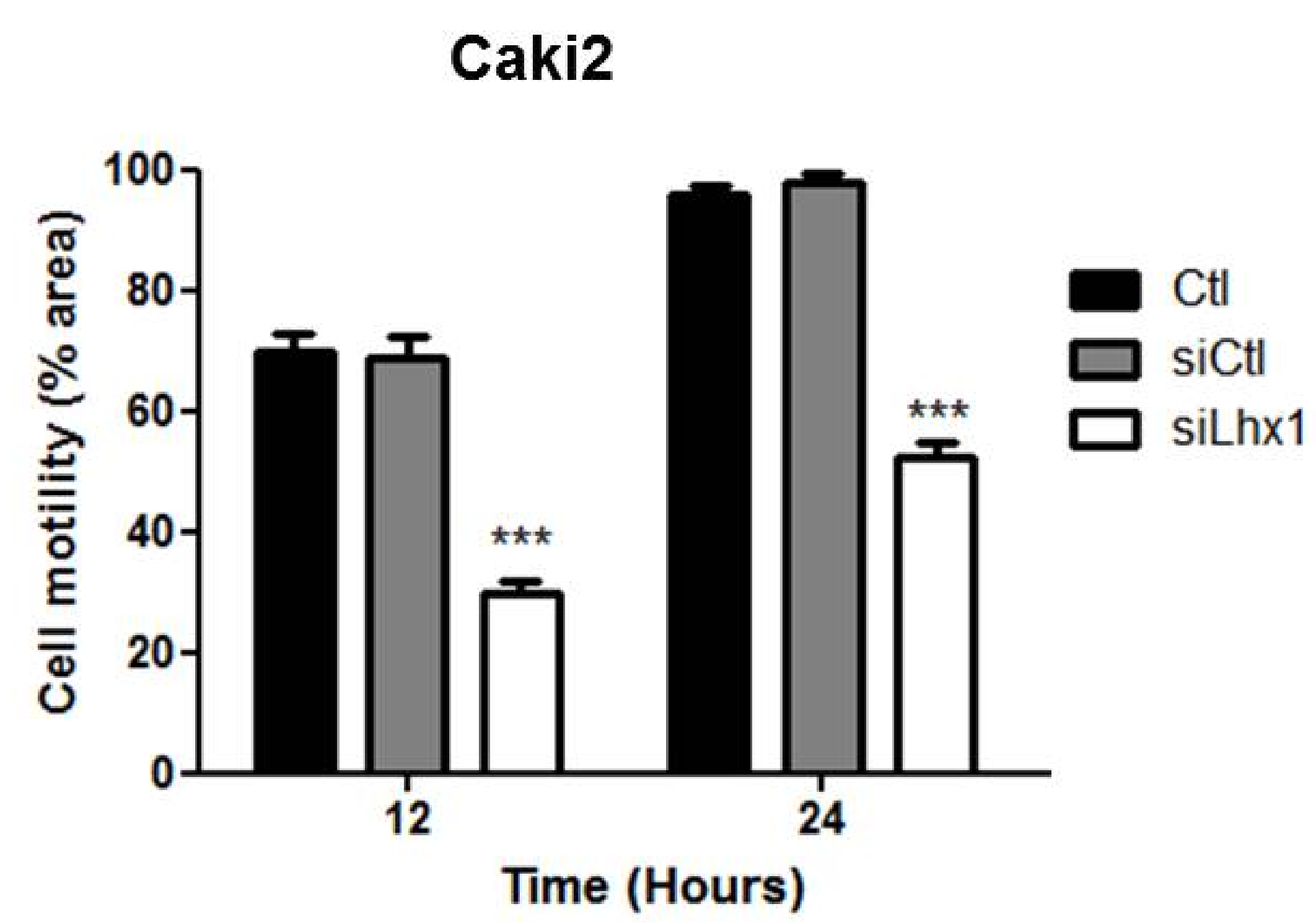

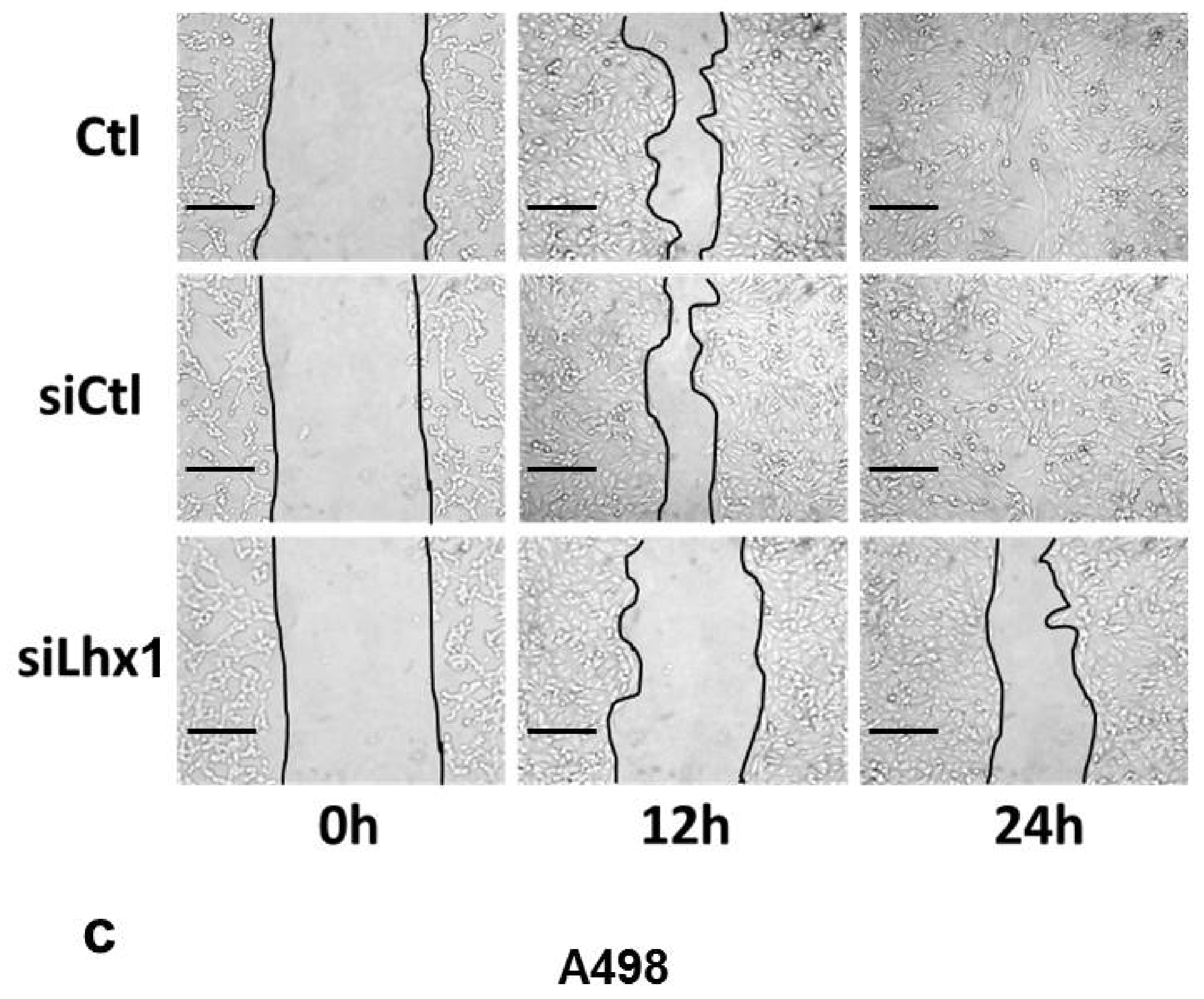

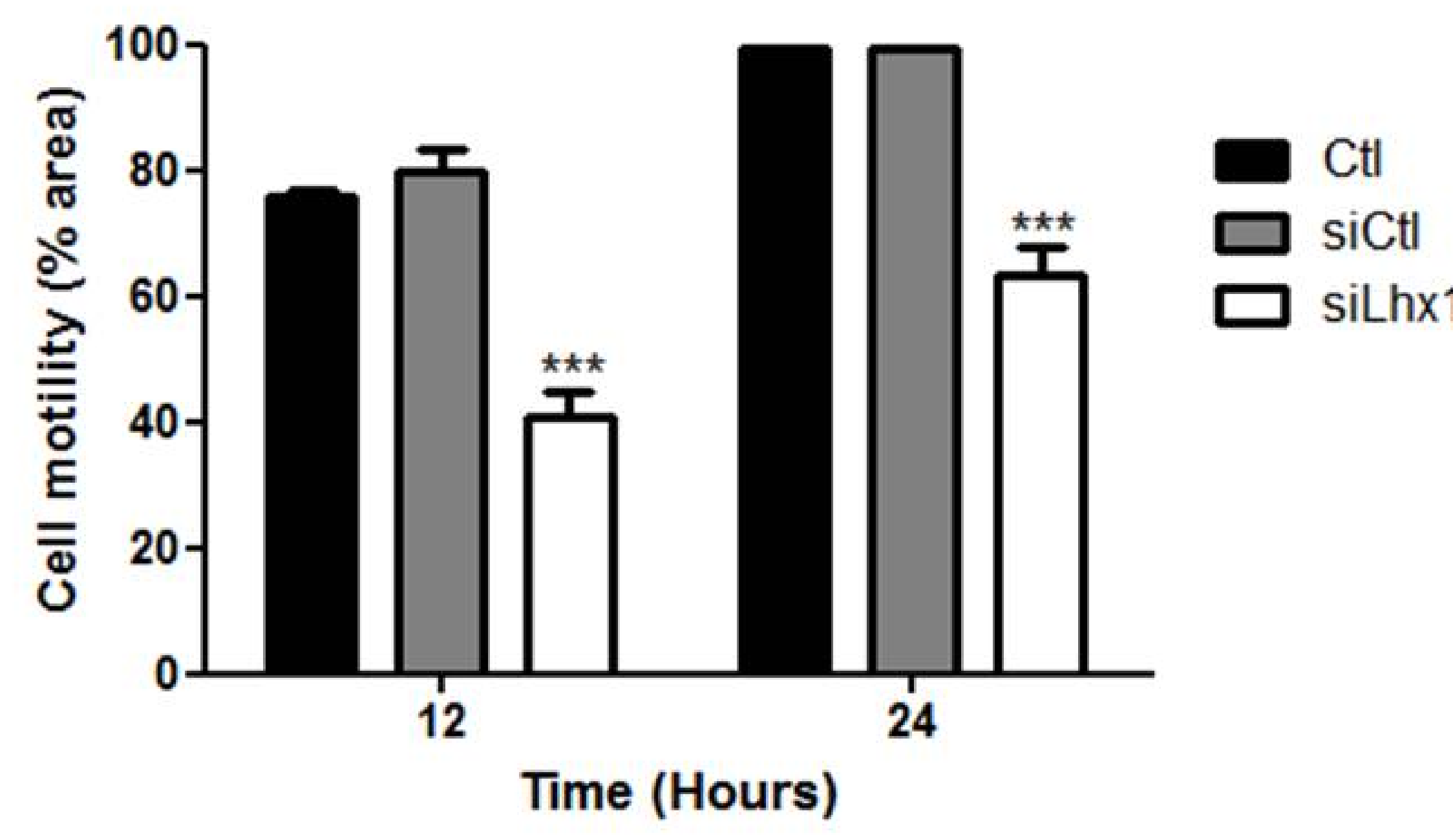


Figure 2

a

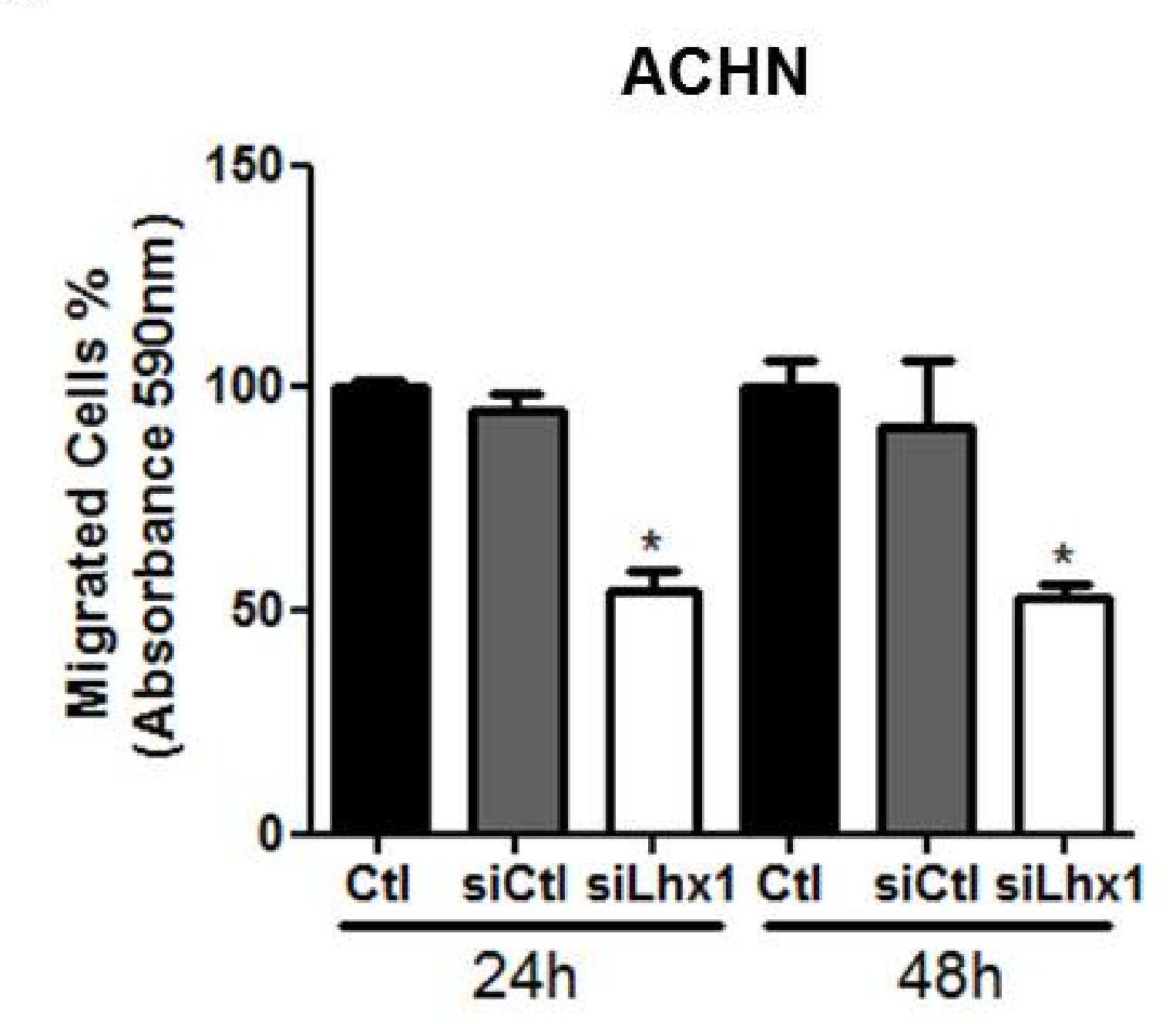

d

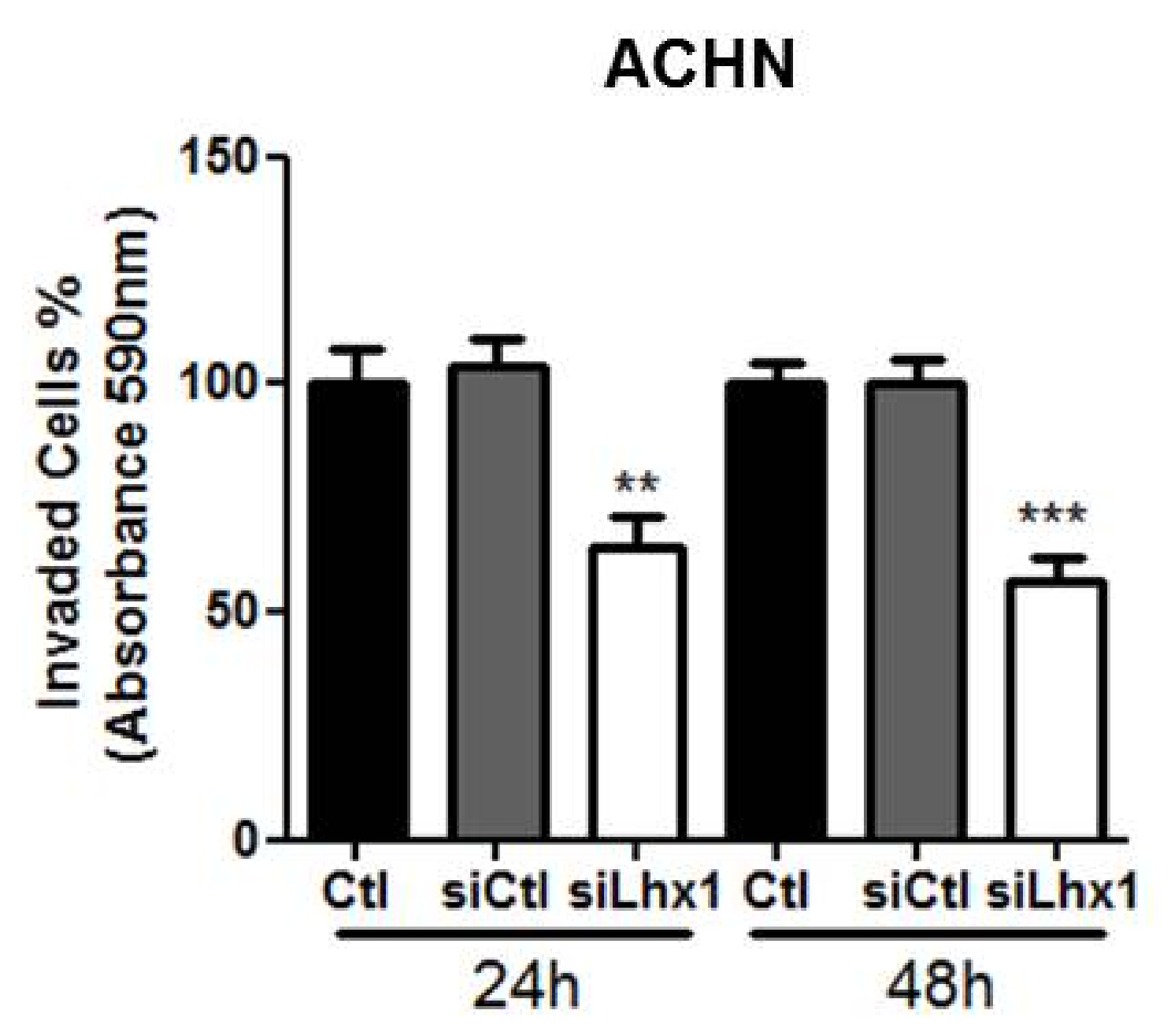

b

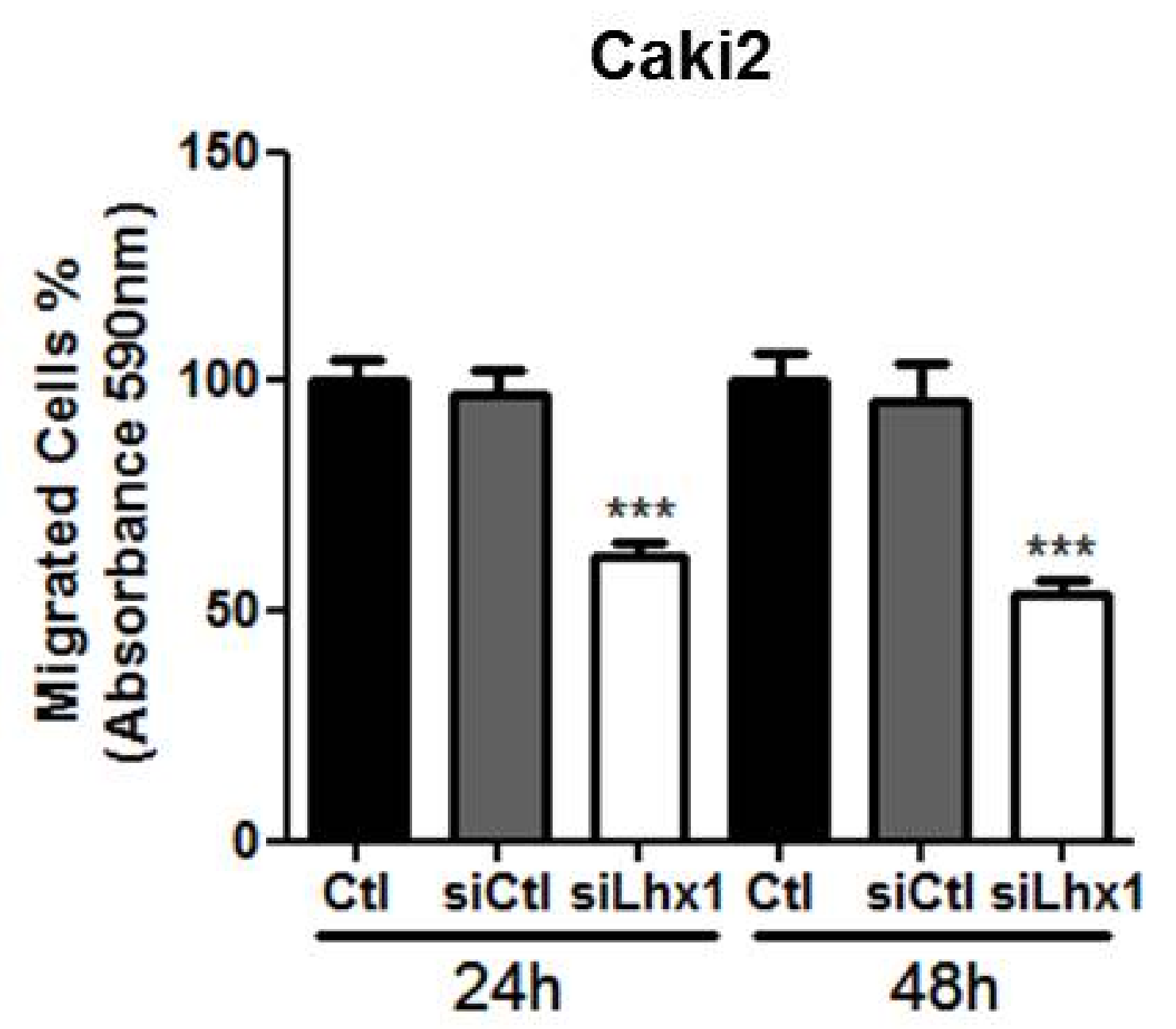

e

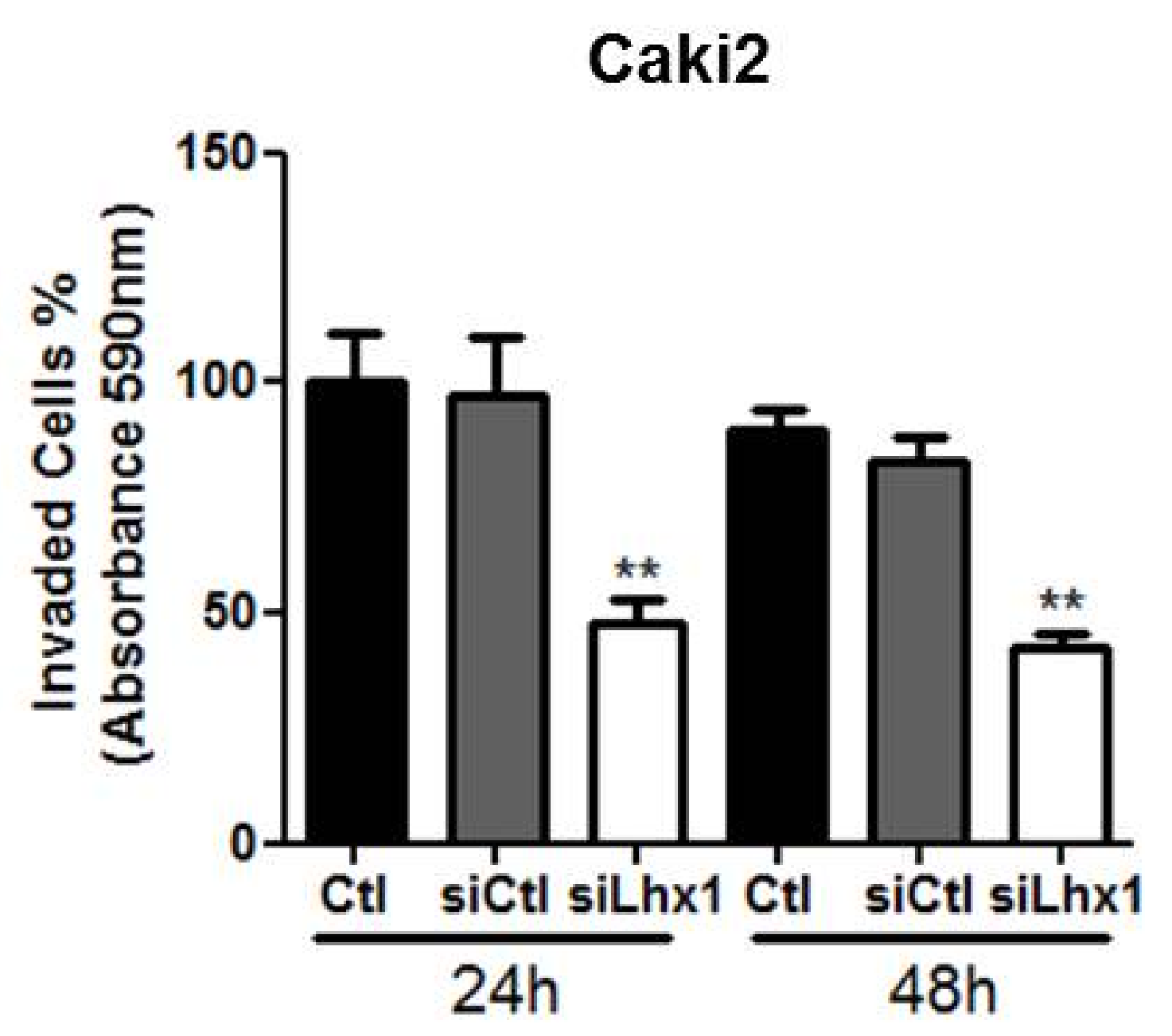

C

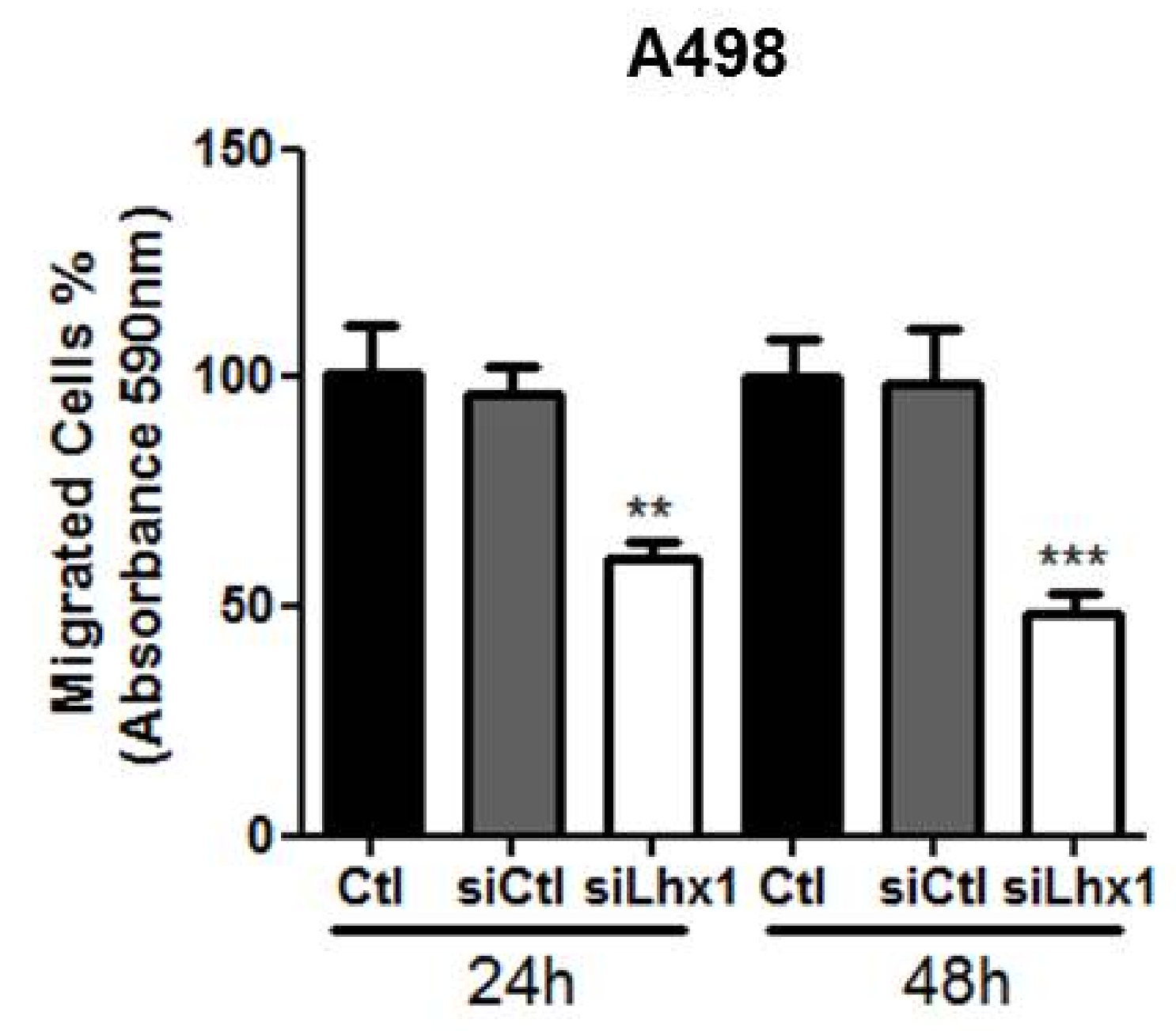

f

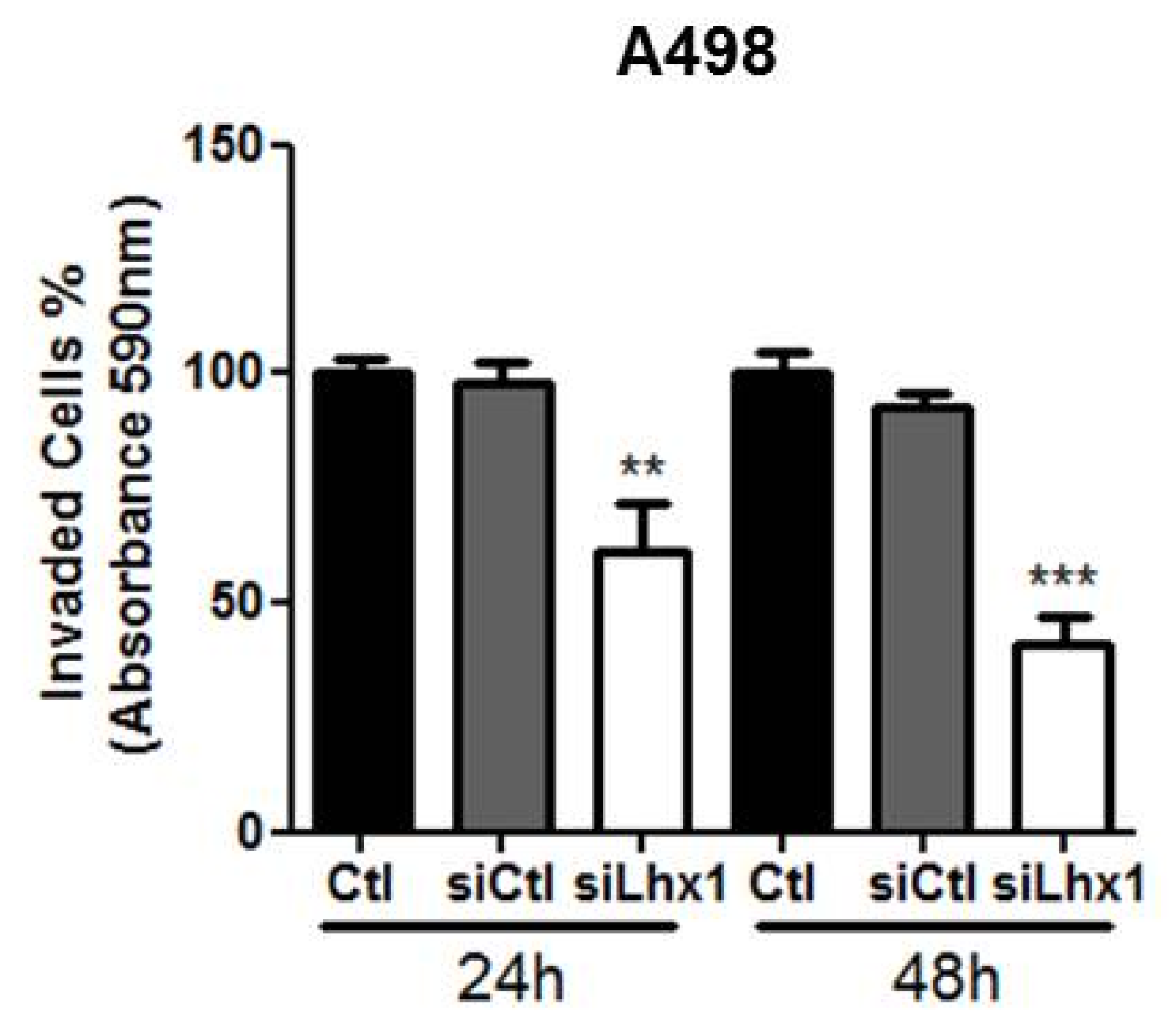


Figure 3

a

\begin{tabular}{|c|c|c|c|c|c|c|c|c|c|}
\hline & \multicolumn{2}{|c|}{$48 \mathrm{~h}$} & \multicolumn{2}{|c|}{$72 \mathrm{~h}$} & \multicolumn{2}{|c|}{$96 \mathrm{~h}$} & \multicolumn{2}{|c|}{$120 \mathrm{~h}$} & \multirow[b]{3}{*}{$105 \mathrm{kDa}$} \\
\hline & Ctl & siLhx1 & Ctl & siLhx1 & CtI & silhx1 & CtI & siLhx1 & \\
\hline TS-1 & & - & & - & & - & - & - & \\
\hline MMP1 & 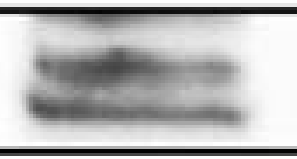 & 5 & $\equiv$ & 5 & & 42 & 2 & -1 & $54 \mathrm{kDa}$ \\
\hline MMP2 & 5 & 10 & $\longrightarrow$ & 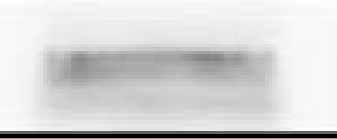 & $\Rightarrow$ & - & 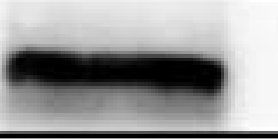 & $m$ & $2 \mathrm{kDa}$ \\
\hline AP3 & $=$ & 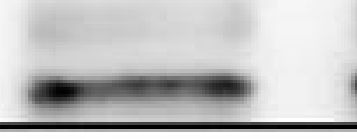 & - & $m$ & -0 & - & - & 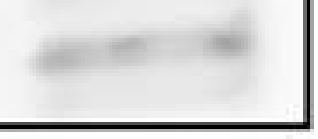 & $55 \mathrm{kDa}$ \\
\hline MMP8 & $=$ & $=$ & $\longrightarrow$ & - & $\longrightarrow$ & $=$ & - & + & $72 \mathrm{kDa}$ \\
\hline 9 & 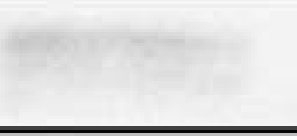 & +4 & $=$ & $=$ & + & $m=$ & $\rightarrow$ & 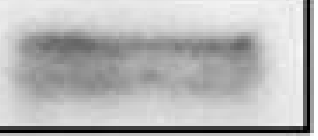 & 92 \\
\hline IMP1 & $m$ & $=$ & & 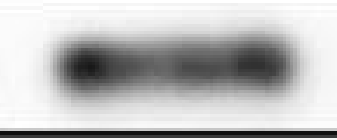 & $=$ & 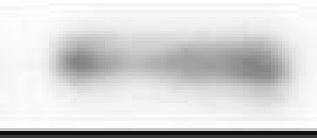 & $+\infty$ & $=$ & $28 \mathrm{kDa}$ \\
\hline
\end{tabular}

b

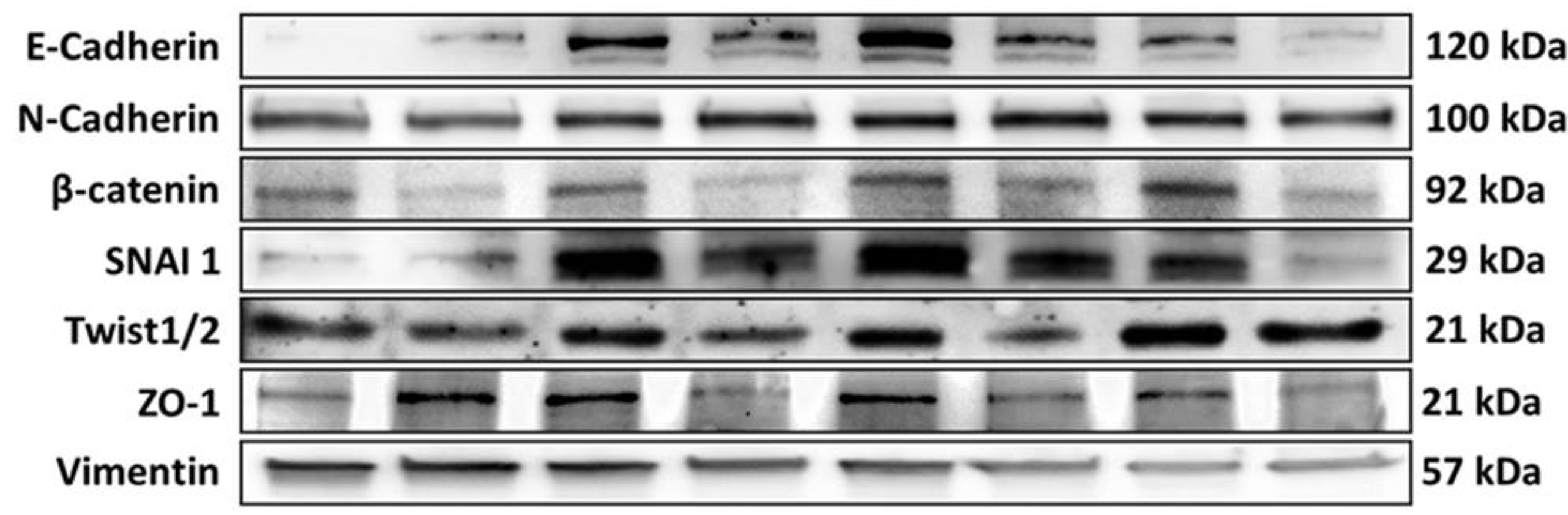

C

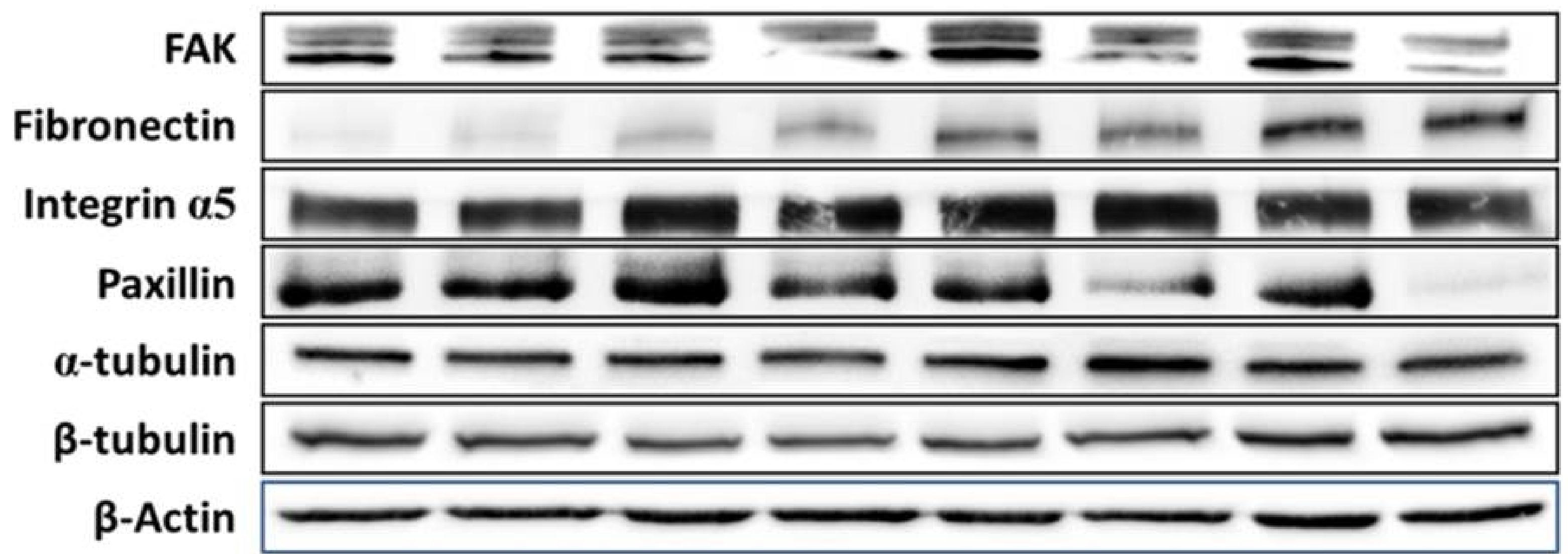

$125 \mathrm{kDa}$ $240 \mathrm{kDa}$ $115 \mathrm{kDa}$ $68 \mathrm{kDa}$ $50 \mathrm{kDa}$ $55 \mathrm{kDa}$ $42 \mathrm{kDa}$

d

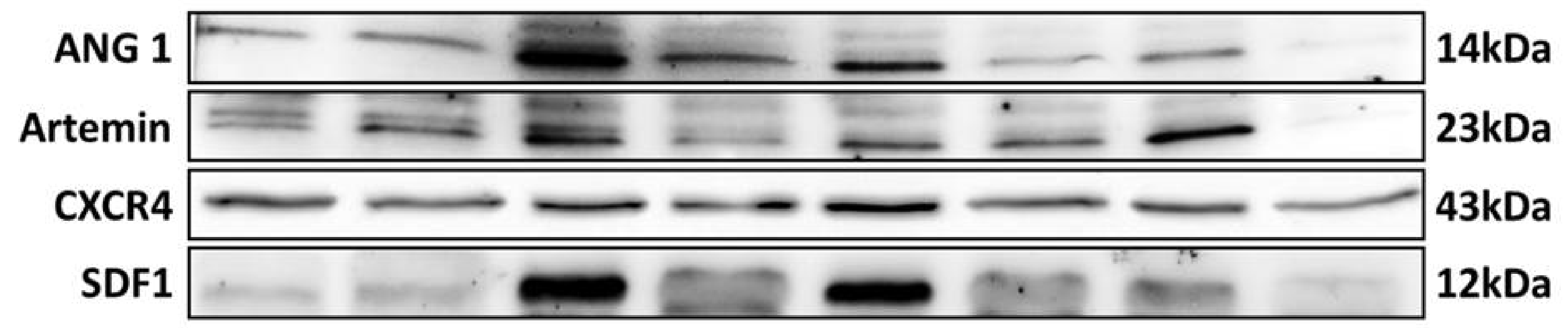


Figure 4

a

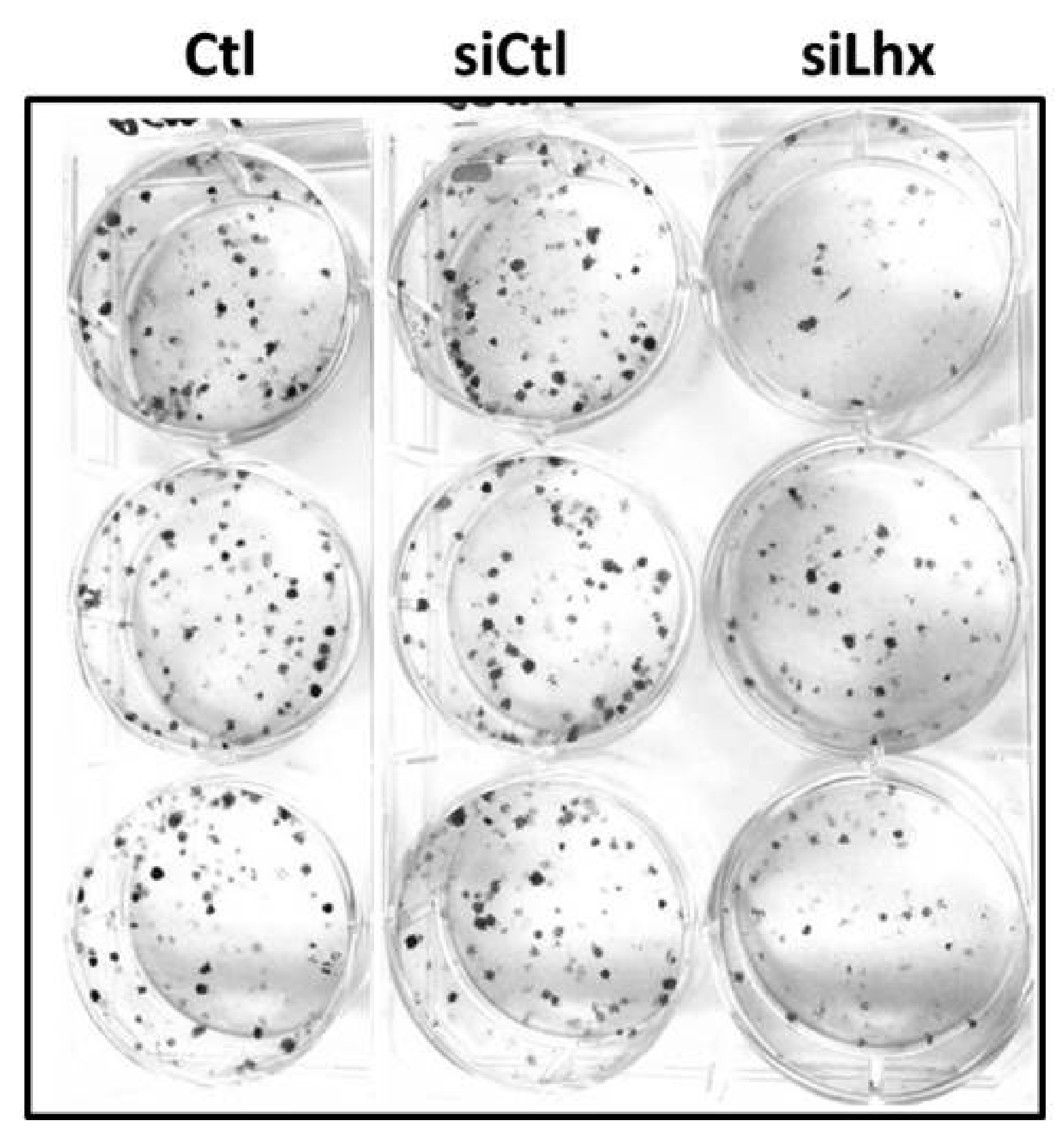

b

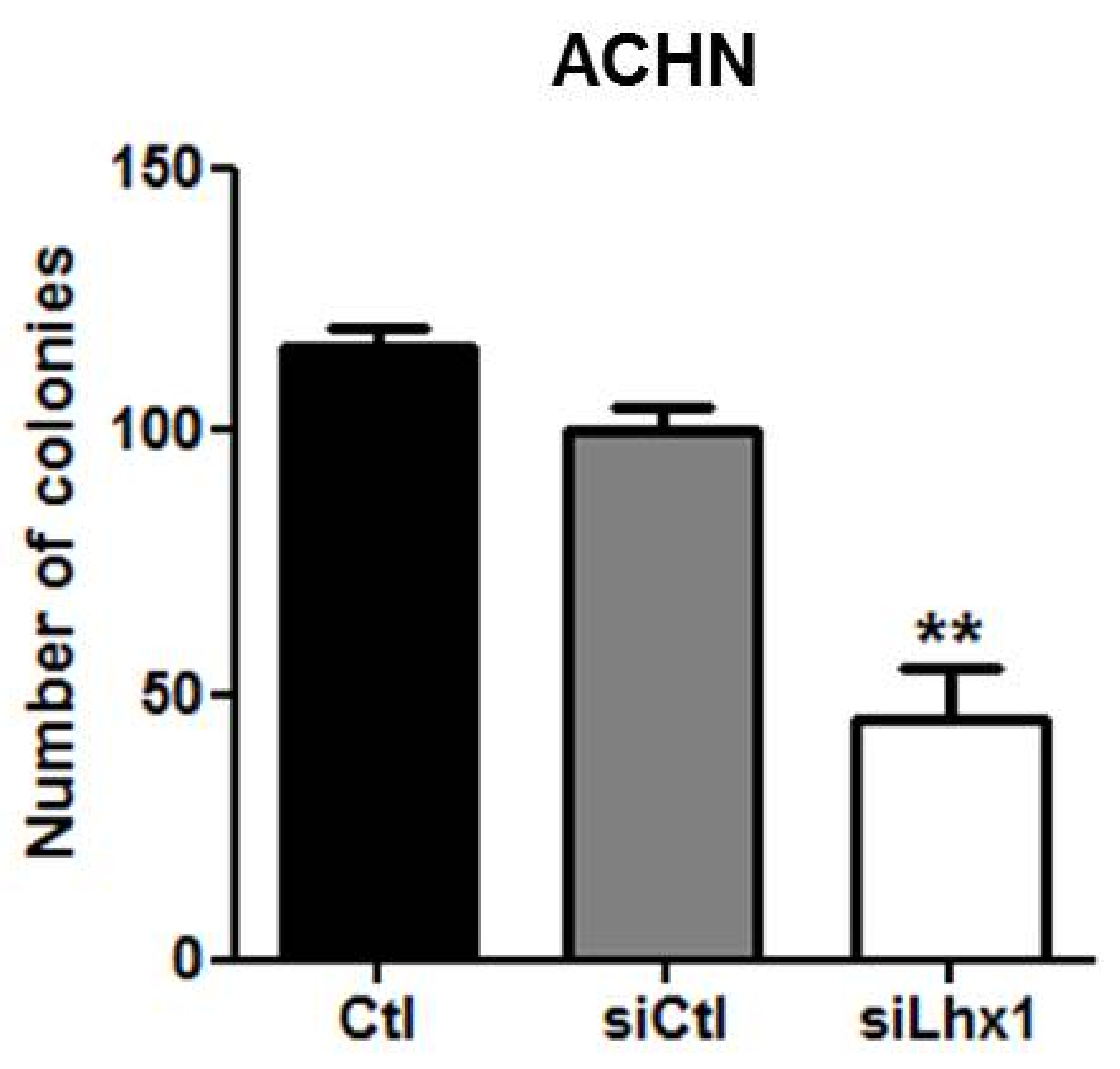

C
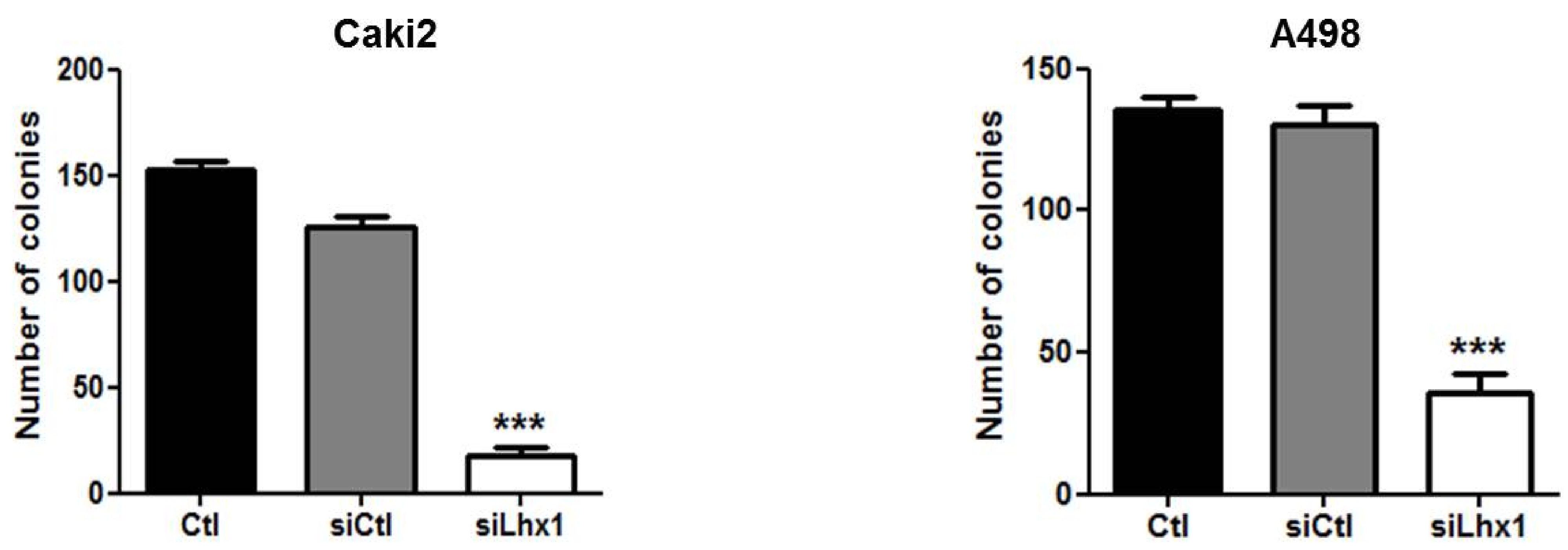


\section{Figure 5}

a

$\frac{\text { RCC3 }}{K \text { Madr }} \frac{\text { RCC8 }}{K \text { K Madr }} \frac{\text { RCC9 }}{K \text { Madr }} \frac{\text { RCC19 }}{\text { K Mgang }} \frac{\text { RCC20 }}{\text { Madr }} \frac{\text { RCC21 }}{\text { Madr }}$

Lim1

\section{$\beta$-Actin}

b

C
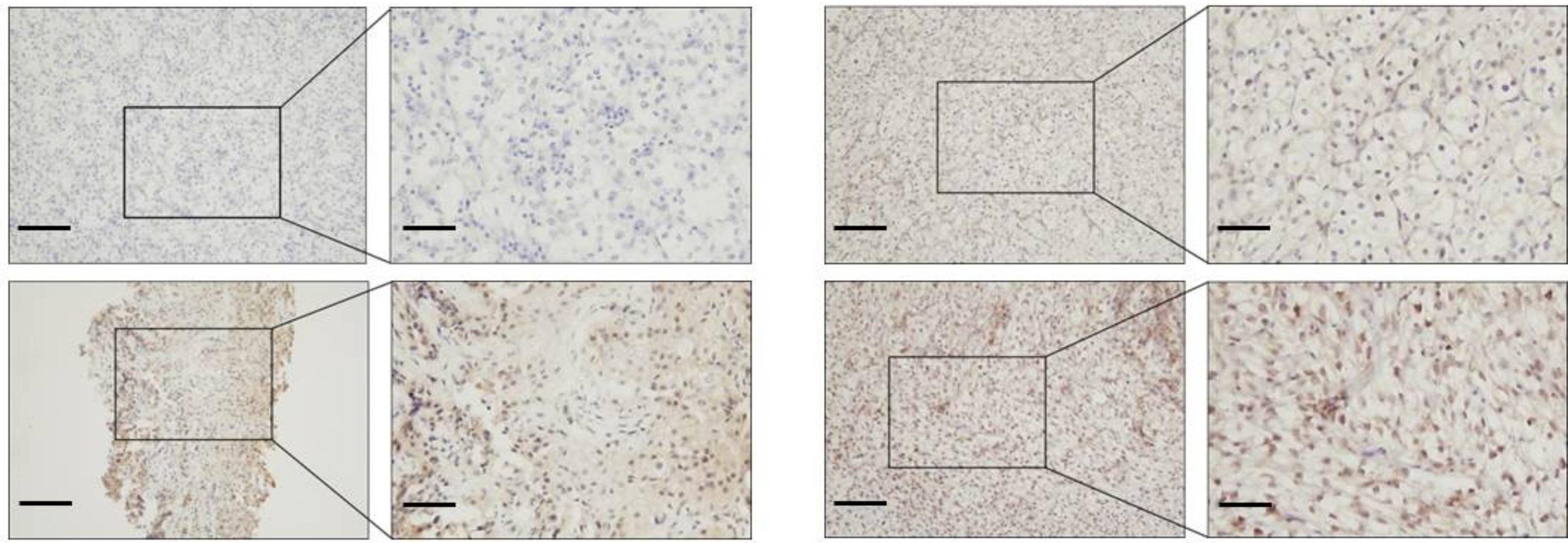

d

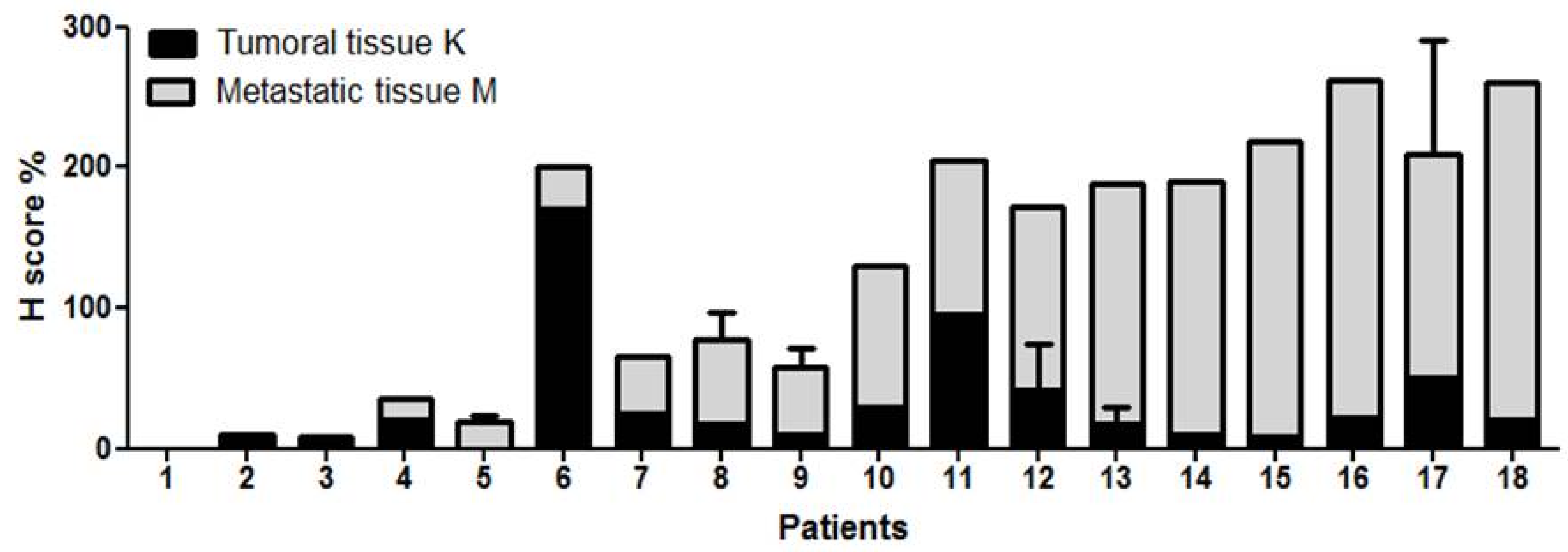

e

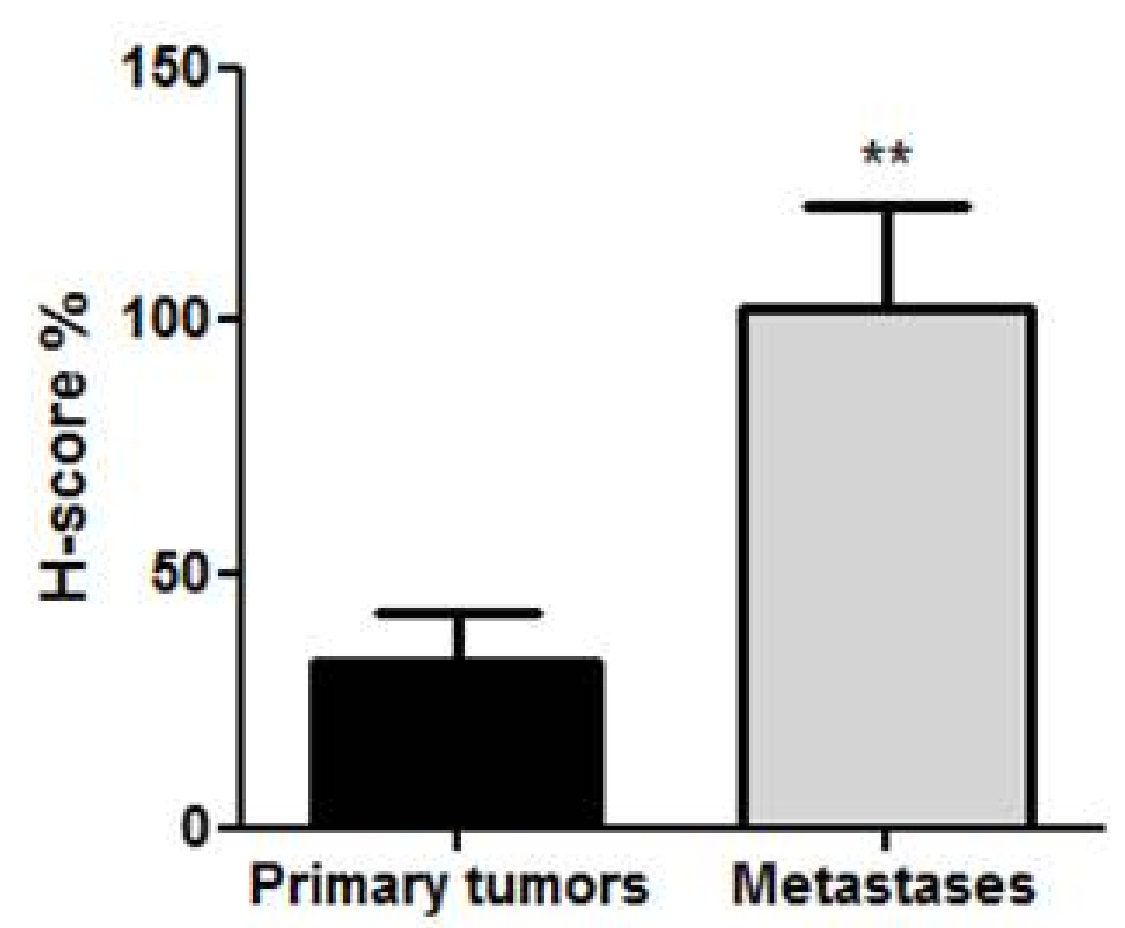

Primary tumors

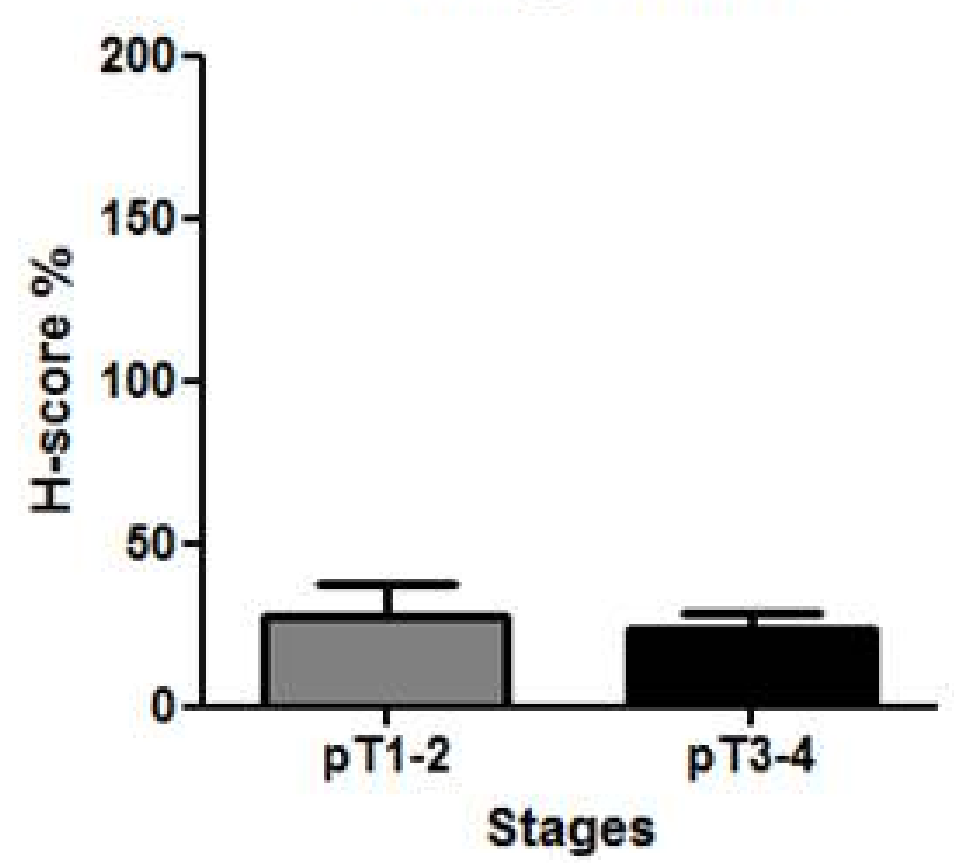

Metastases

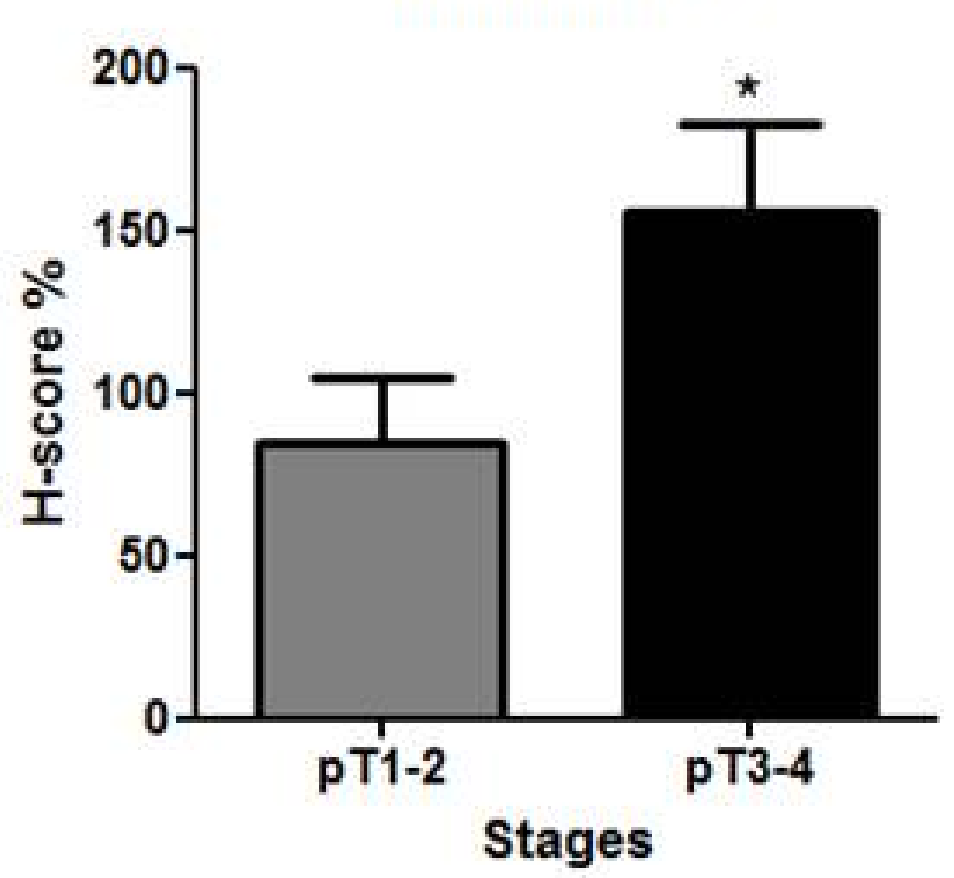




\section{Figure 6}

a

Caki2

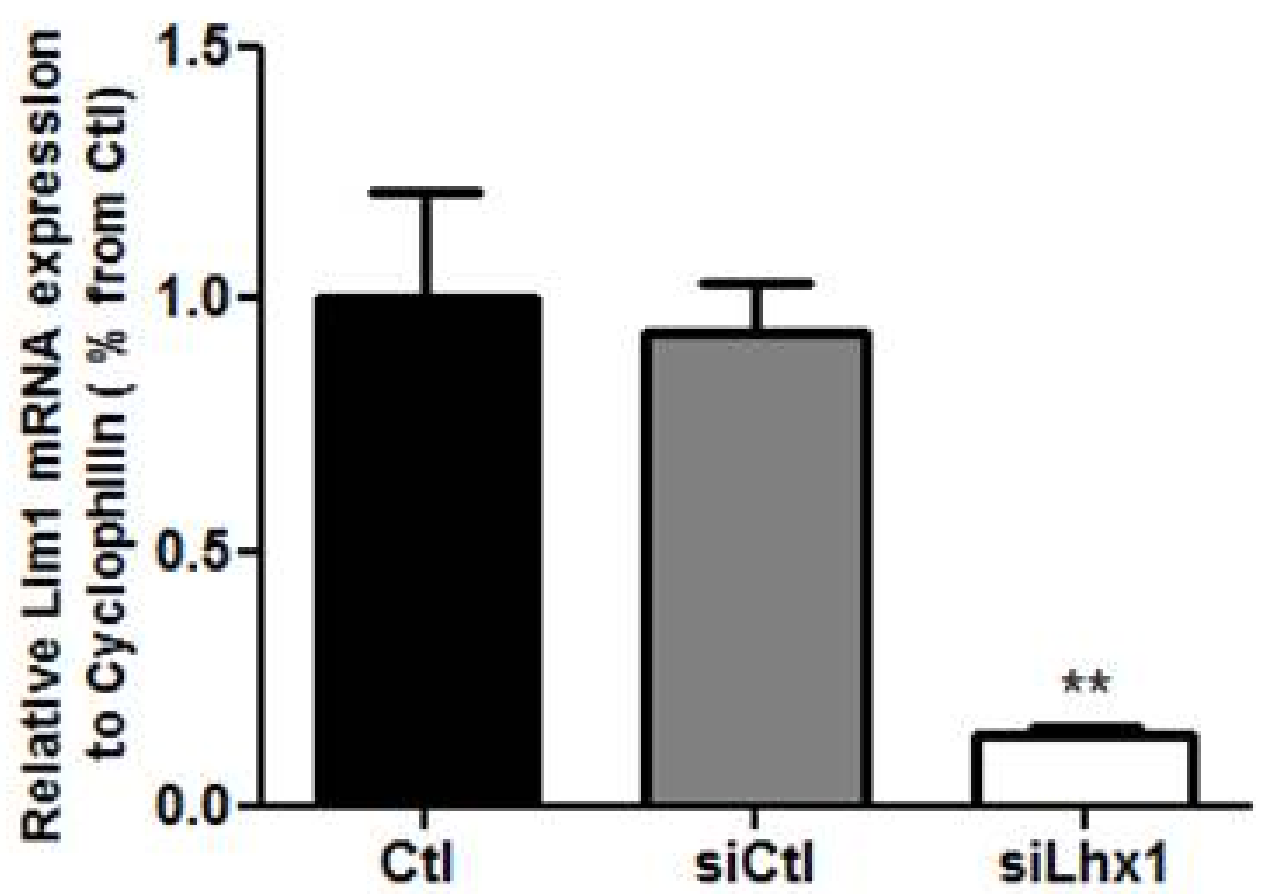

Caki2

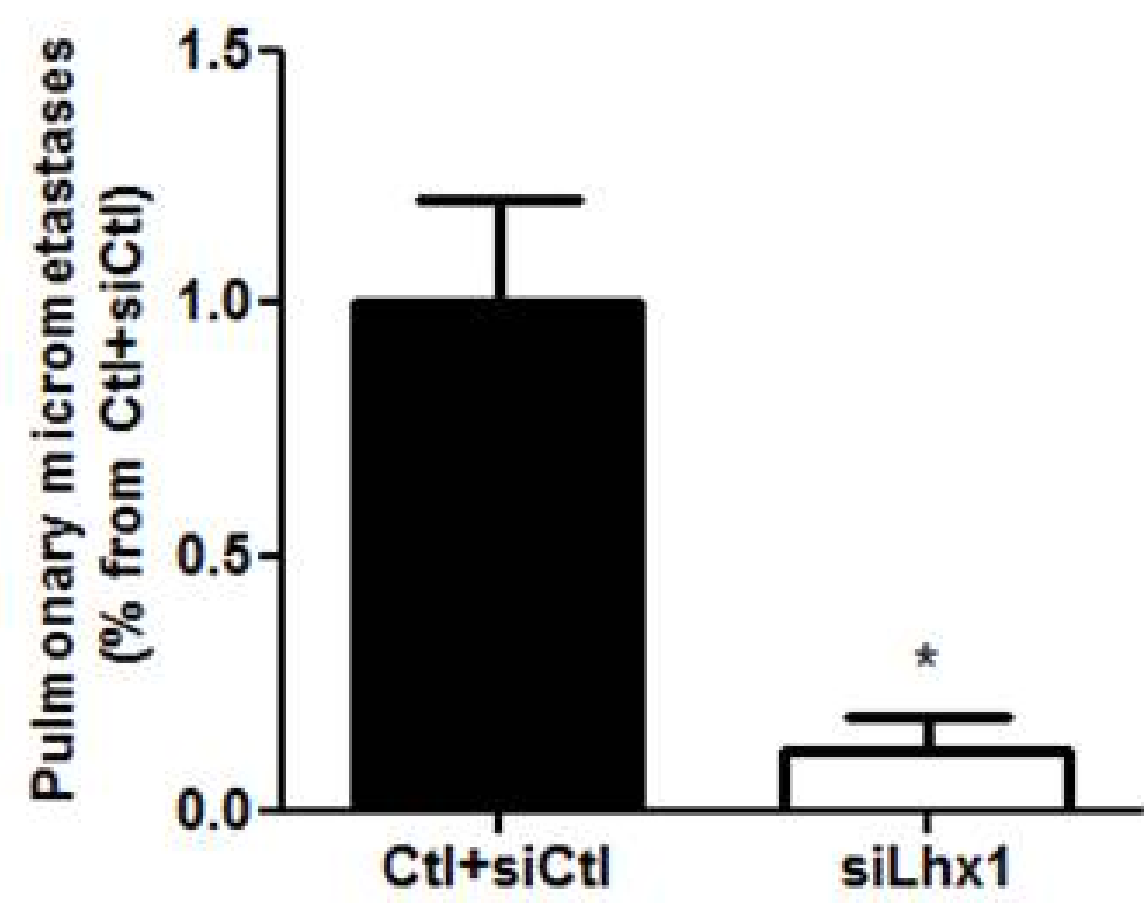

C

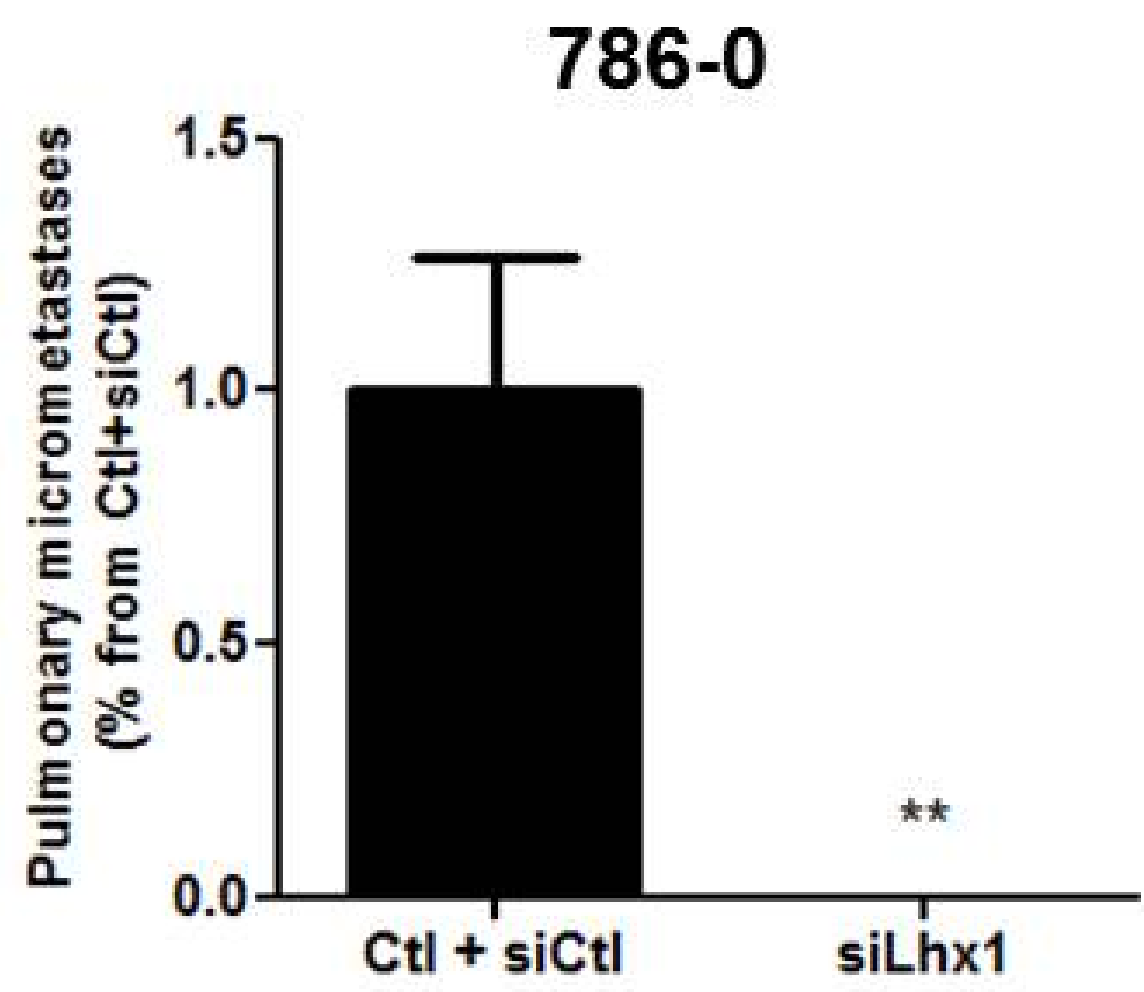

786-0

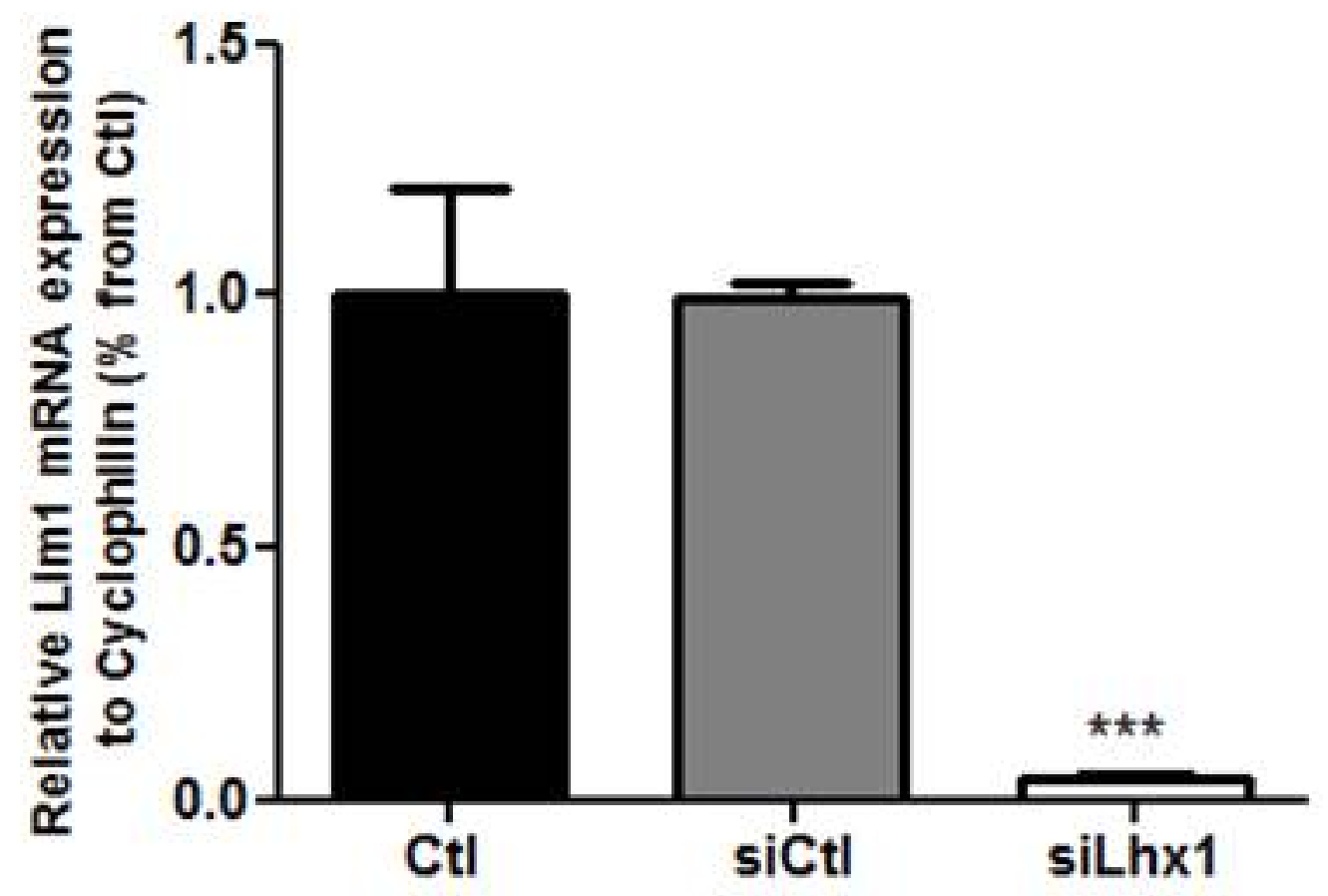

Caki2

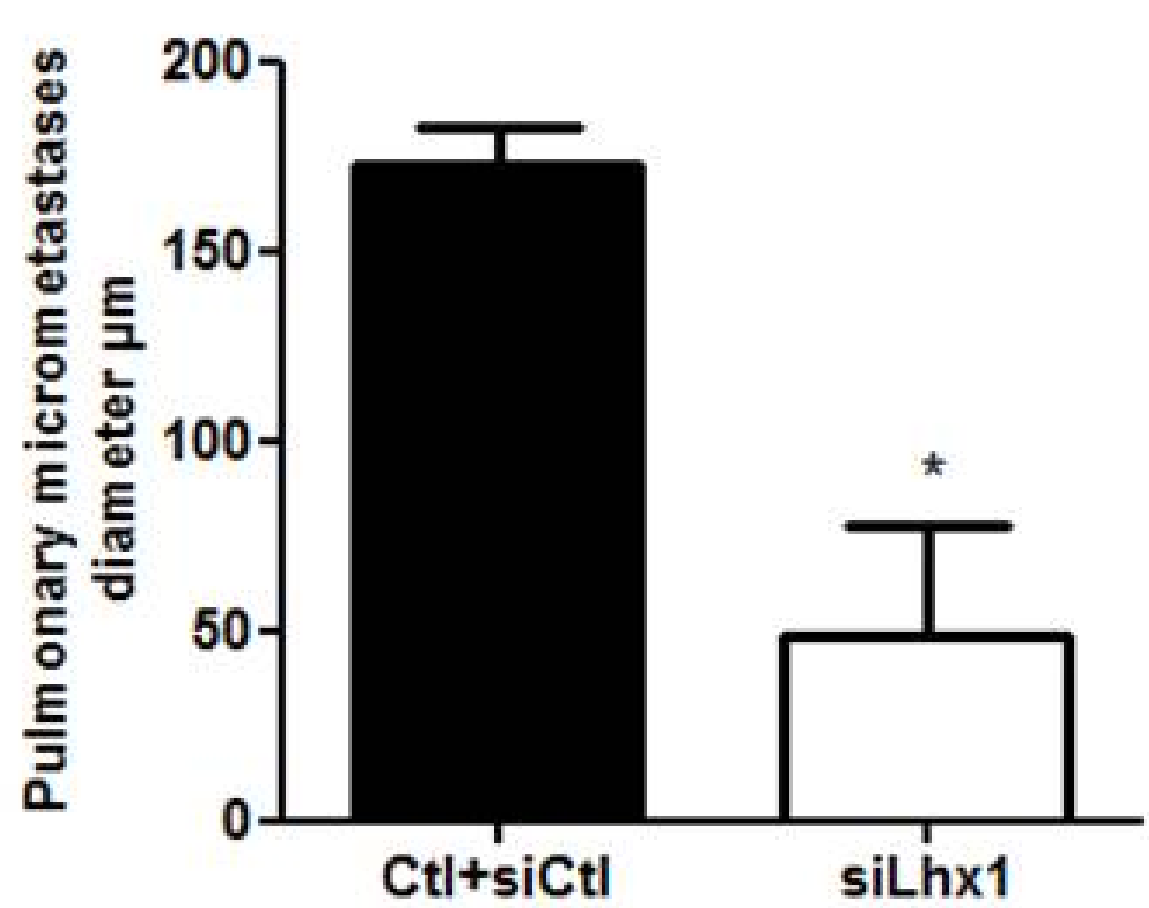

786-0

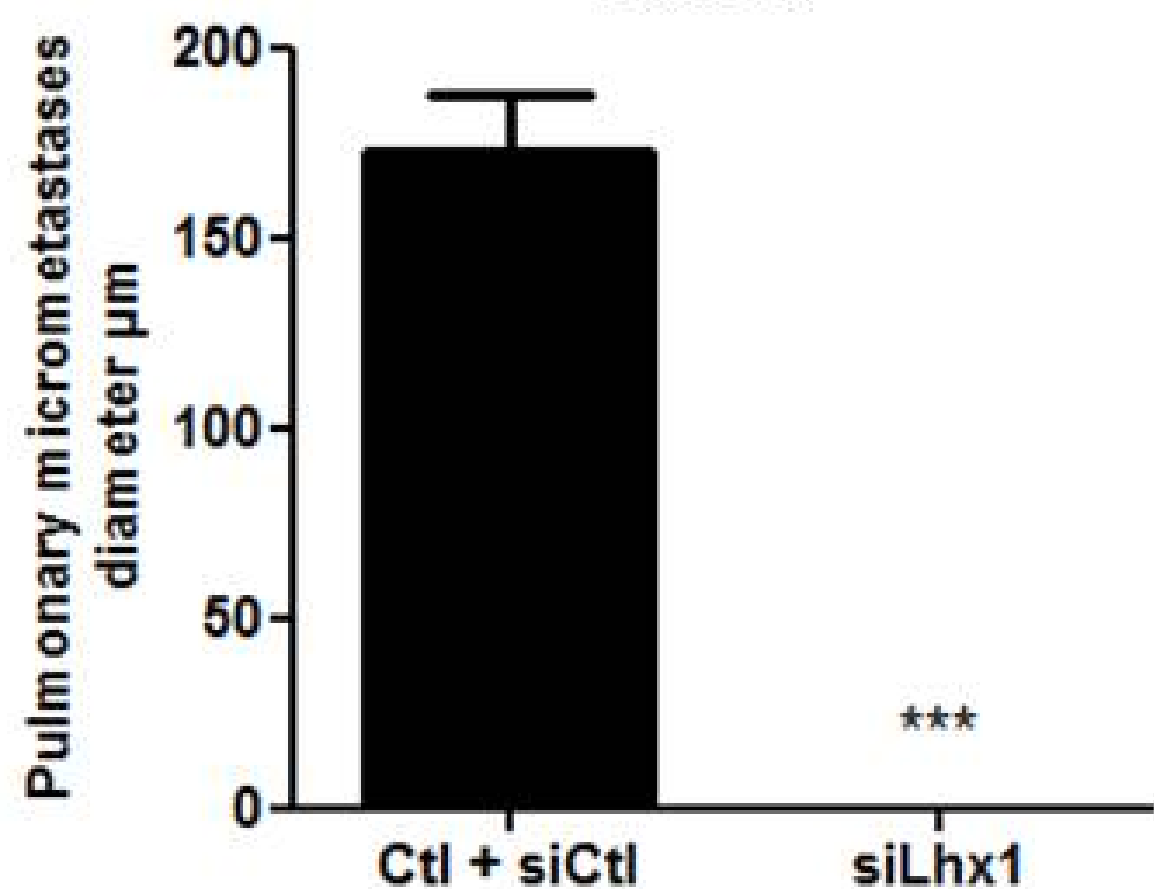

d

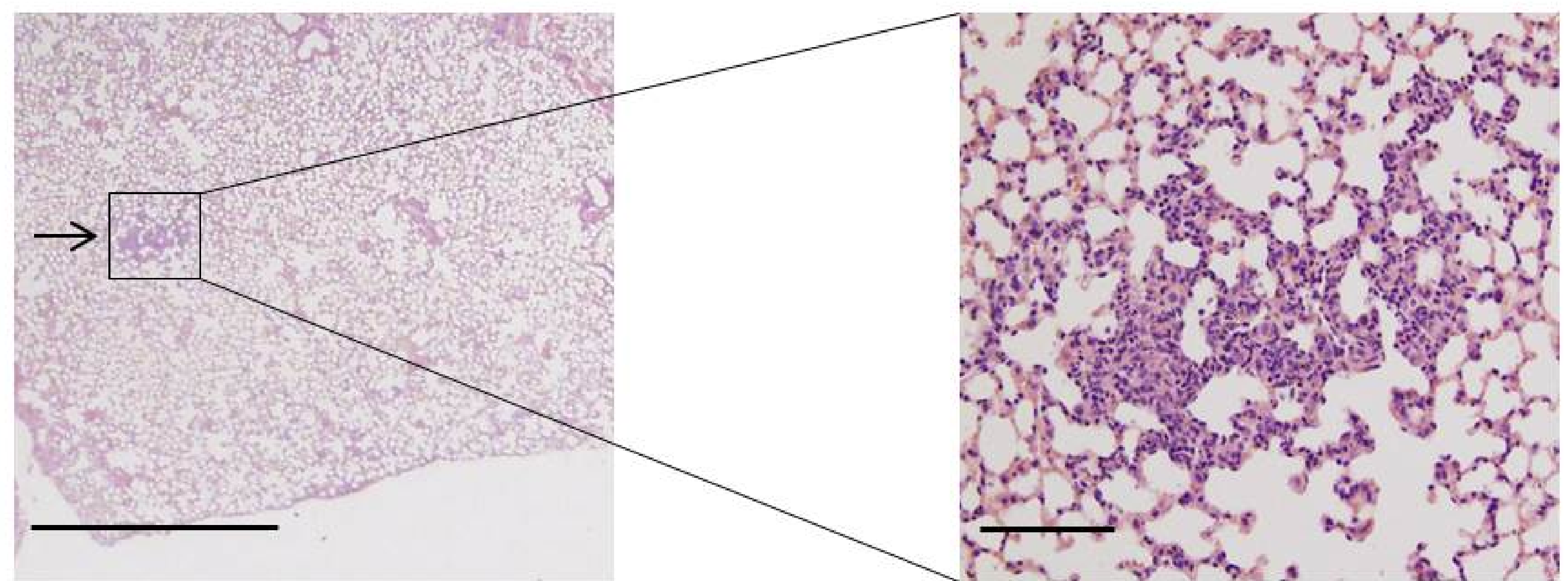

